\title{
Decoupling of the Agulhas Leakage from the Agulhas Current
}

\author{
BENJAMIN R. LOVEDAY \\ Department of Oceanography, University of Cape Town, Cape Town, South Africa \\ JONATHAN V. DURGADOO \\ GEOMAR Helmholtz Centre for Ocean Research Kiel, Kiel, Germany \\ CHRIS J. C. REASON \\ Department of Oceanography, University of Cape Town, Cape Town, South Africa
}

ARNE BIASTOCH

GEOMAR Helmholtz Centre for Ocean Research Kiel, Kiel, Germany

PIERRICK PENVEN

LMI ICEMASA, Laboratoire de Physique des Océans, UMR 6523 (CNRS, IFREMER, IRD, UBO), Brest, France

(Manuscript received 18 April 2013, in final form 22 January 2014)

\begin{abstract}
The relationship between the Agulhas Current and the Agulhas leakage is not well understood. Here, this is investigated using two basin-scale and two global ocean models of incrementally increasing resolution. The response of the Agulhas Current is evaluated under a series of sensitivity experiments, in which idealized anomalies, designed to geometrically modulate zonal trade wind stress, are applied across the Indian Ocean Basin. The imposed wind stress changes exceed plus or minus two standard deviations from the annual-mean trade winds and, in the case of intensification, are partially representative of recently observed trends. The Agulhas leakage is quantified using complimentary techniques based on Lagrangian virtual floats and Eulerian passive tracer flux. As resolution increases, model behavior converges and the sensitivity of the leakage to Agulhas Current transport anomalies is reduced. In the two eddy-resolving configurations tested, the leakage is insensitive to changes in Agulhas Current transport at $32^{\circ} \mathrm{S}$, though substantial eddy kinetic energy anomalies are evident. Consistent with observations, the position of the retroflection remains stable. The decoupling of Agulhas Current variability from the Agulhas leakage suggests that while correlations between the two may exist, they may not have a clear dynamical basis. It is suggested that present and future Agulhas leakage proxies should be considered in the context of potentially transient forcing regimes.
\end{abstract}

\section{Introduction}

South of Africa, the Agulhas Current (AC) retroflects, turning sharply eastward and flowing back into the Indian Ocean. The Agulhas leakage (AL), a collective term for waters that persist into the South Atlantic after ejection from this retroflection, forms a key link in the warm-water

\footnotetext{
Corresponding author address: Ben Loveday, Room 123, RW James Building, Residence Road, University of Cape Town, Cape Town 7700, South Africa.

E-mail: ben.loveday@gmail.com
}

route of the global thermohaline circulation (Beal et al. 2011; Gordon 1986). Long-term variability in the exchange of these waters may have consequences for the interdecadal strength of the Atlantic meridional overturning circulation (Weijer et al. 2002; Biastoch et al. 2008b) and possibly plays a role in the termination of glacial phases (Peeters et al. 2004). Leakage magnitude is mediated by the dynamics of the greater Agulhas system, under the influence of the large-scale winds (de Ruijter et al. 1999; Biastoch et al. 2008c; Rouault et al. 2009; van Sebille et al. 2009; Zharkov and Nof 2008). Reanalysis products show that Indian Ocean trade winds have 
recently intensified (Backeberg et al. 2012). However, an unclear western boundary response during this period (Biastoch et al. 2009b; Rouault et al. 2009) suggests a need to clarify the response of the Agulhas Current and leakage to trade wind variability.

Agulhas leakage predominantly occurs via rings, occluded from the retroflection at a rate of $5 \pm 1 \mathrm{yr}^{-1}$ (Schouten et al. 2002), with secondary contributions from cyclonic eddies (Hall and Lutjeharms 2011) and filaments (Lutjeharms and Cooper 1996; Whittle et al. 2008). These contribute to a turbulent Cape Basin that is difficult to measure directly. Consequently, leakage observations are highly variable at $2-15$ Sverdrups $(\mathrm{Sv}$; $1 \mathrm{~Sv} \equiv 10^{6} \mathrm{~m}^{3} \mathrm{~s}^{-1}$ ) (de Ruijter et al. 1999; Richardson 2007). In contrast, the southern Agulhas Current is better constrained at $\sim 70 \mathrm{~Sv}$ (Bryden et al. 2005). However, theoretical arguments suggest the existence of an exploitable dynamical relationship between Agulhas Current transport and downstream leakage, allowing the latter to be inferred (Beal et al. 2009; van Sebille et al. 2010a).

The mechanistic interplay between the current and leakage has been extensively studied using idealized numerical simulations that focus on Agulhas retroflection dynamics. Using a weakly nonlinear, one-layer model, de Ruijter (1982) argues that inertia allows the Agulhas Current to overshoot the continental shelf as a free jet and is critical in establishing the retroflection. Positive vorticity accumulation in the polewardflowing jet turns it eastward, forming an Agulhas Return Current (RC) with a transport determined by the decrease in wind stress curl across the inertial boundary layer. Here, a larger decrease produces a stronger return current, and in consequence, a weaker leakage. Boudra and de Ruijter (1986) and de Ruijter and Boudra (1985) confirm this inertial relationship in baroclinic and barotropic cases. Subsequently, Ou and de Ruijter (1986) show that stronger upstream transport causes an earlier coastal separation and a more eastward retroflection position. Although retroflections are possible in high-friction cases (Boudra and Chassignet 1988; Chassignet and Boudra 1988), only those governed by inertia are physically valid (Dijkstra and de Ruijter 2001), as high friction produces a nonphysical barrier to interocean transport in the former case. Recently, Le Bars et al. (2012) describe a third regime where leakage reaches an asymptotic limit at high wind stress due to increased cross-frontal mixing in the return current and the southward export of Indian Ocean waters.

Indian Ocean winds have recently undergone substantial change. Reanalysis products show a positive trend in wind stress curl between $18^{\circ}$ and $25^{\circ} \mathrm{S}$ from 1993 to 2009 (Backeberg et al. 2012), predominantly driven by trade wind intensification (Han et al. 2010). Concurrently, a strengthening (Swart and Fyfe 2012) and poleward migration (Thompson and Solomon 2002; Gillett and Thompson 2003) of the Southern Hemisphere westerlies has intensified the supergyre linking the southern Indian, South Atlantic, and South Pacific Oceans (Cai 2006).

Reanalysis-forced hindcasts, performed with highresolution ocean models, suggest that, post-1970, these wind changes have driven a substantial leakage increase (Biastoch et al. 2009b; Rouault et al. 2009), warming the South Atlantic (Lee et al. 2011). Although both hindcasts show a warming of the Agulhas Current in this period, Biastoch et al. (2009b) show a weakening, while Rouault et al. (2009) record a strengthening Agulhas Current. Analyzing the Biastoch et al. (2009b) simulation, van Sebille et al. (2009) argue that the anticorrelation between reduced current strength and increased leakage has a dynamical basis, following the inertial outcropping mechanism of Ou and de Ruijter (1986). However, Ou and de Ruijter (1986) do not discuss leakage in their idealized study, and altimetry suggests that the position of the retroflection has remained constant since 1992 (Dencausse et al. 2010; Backeberg et al. 2012).

Notably, the Biastoch et al. (2009b) and Rouault et al. (2009) hindcasts apply different reanalysis forcing. Superimposed trade and westerly wind signals may produce nonlinear effects that are difficult to disentangle. In this context, investigating a dynamical link between the Agulhas Current and leakage is problematic as responses to upstream transport changes cannot be readily isolated from westerly induced effects farther south. Using similar models to this study, Durgadoo et al. (2013) show a strong leakage response to changes in westerly wind strength. However, inertial arguments suggest that Agulhas Current transport may also influence leakage. As recent observations show that trade winds, which partially drive current strength, are intensifying, two questions become apparent. First, how does the Agulhas Current respond to trade wind-driven variability? Second, what are the consequences for Agulhas leakage?

Here, using four ocean models of increasing horizontal resolution, we test the sensitivity of the greater Agulhas Current system to changes in the trade wind stress that mirror and exceed the recent trends seen in the reanalysis products (Backeberg et al. 2012). We demonstrate that the inertia of the Agulhas Current, driven by these changes, has a minimal influence on the magnitude of the Agulhas leakage, a "decoupling" that becomes more pronounced as resolution increases. We conclude that, in the eddy-resolving simulations tested here, the upstream transport of the Agulhas Current may not be a reliable proxy for the Agulhas leakage. 


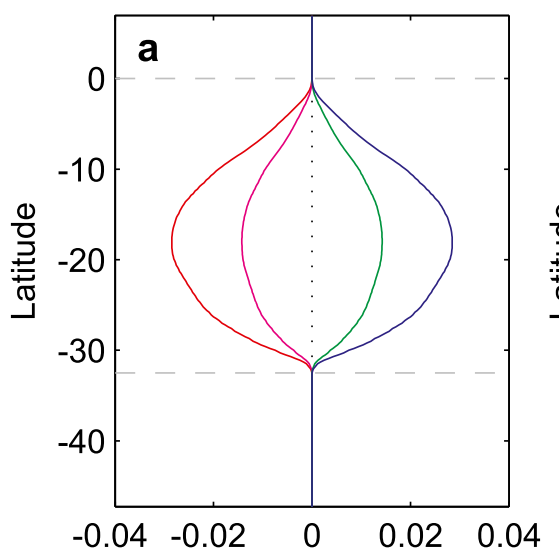

Zonal Wind Stress Anomaly $\left[\mathrm{Nm}^{-2}\right]$

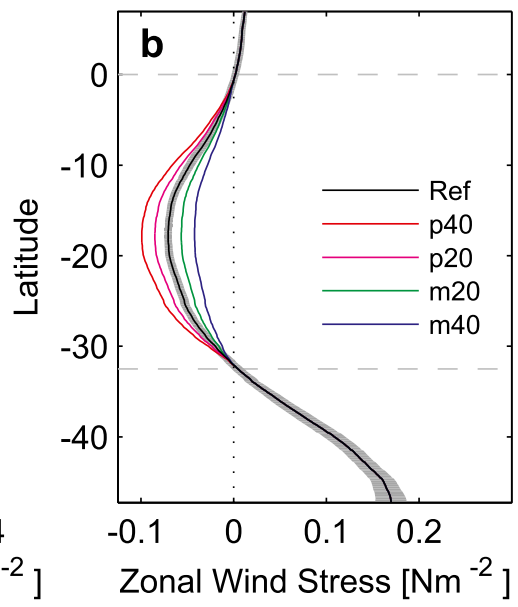

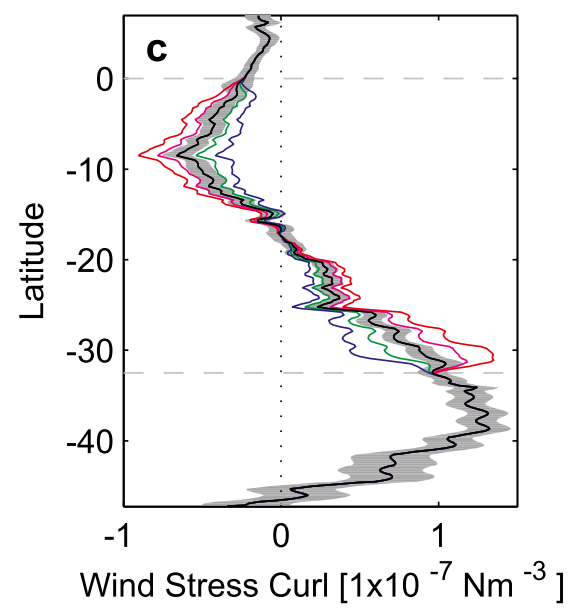

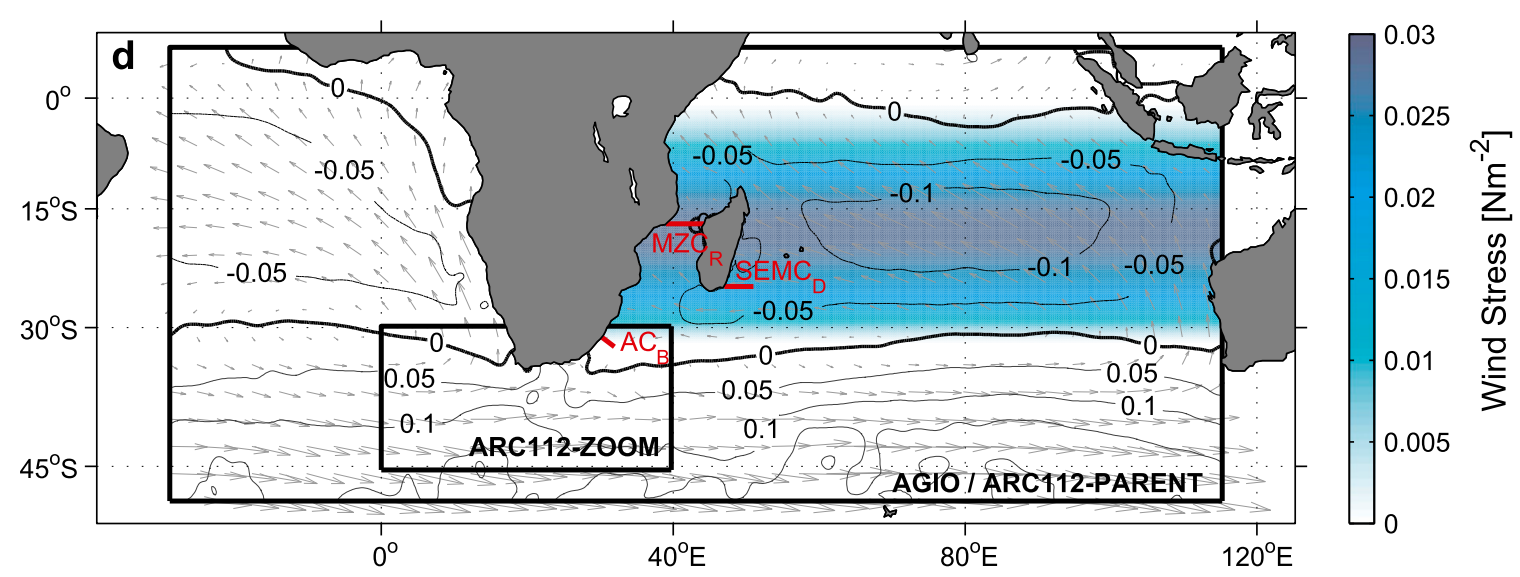

FIG. 1. Zonal averages of (a) zonal wind stress anomalies, (b) zonal wind stress, and (c) zonal wind stress curl for the trade wind sensitivity experiments. No anomaly is applied outside of the gray dashed lines. The black line describes the 20 -yr mean climatological reference value. The gray shaded area in (b) and (c) covers the annual std dev in the 1948-2007 wind stress curl extracted from the ARC112i hindcast. (d) The full extent of the AGIO and ARC112 parent domain is shown by the large black box. Anomalies are applied over the area shown in color; AGIOm40 is shown in this case. The contours and vectors show the magnitude and direction of the AGIO, wind stress. The extent of the ARC112 high-resolution nest is shown by the small black box. The $\mathrm{AC}_{B}, \mathrm{SEMC}_{D}$, and $\mathrm{MZC}_{R}$ sections are derived from Bryden et al. (2005), Donohue and Toole (2003), and Ridderinkhof and de Ruijter (2003), respectively, and are used to make comparisons with observations (Table 3 ).

\section{Methods}

\section{a. Modifying trade wind stress}

Between 1993 and 2009, reanalysis products show a positive trend in wind stress curl between $10^{\circ}$ and $26^{\circ} \mathrm{S}$ (Backeberg et al. 2012, their supplemental materials), driven by trade wind intensification (Han et al. 2010). Although this variability influences Agulhas Current transport (Rouault et al. 2009), the effect on the leakage is unknown. To investigate this response we developed a series of anomalies that modify the winds between the equator and $32.5^{\circ} \mathrm{S}$, which we assume as the trade winds. The anomalies are based on the zonally averaged zonal wind stress from $20^{\circ}$ to $115^{\circ} \mathrm{E}$, as extracted from a climatological reference run forced with the Coordinated Ocean-Ice Reference Experiments, version $2 \mathrm{~b}$ (CORE v.2b), normal-year surface fluxes (Large and Yeager 2009). The anomalies are designed to geometrically modulate zonal trade wind stress strength by $\pm 20 \%$ and $\pm 40 \%$ (Fig. 1). The meridional wind stress is unchanged. The $\pm 20 \%$ anomalies cause a change in wind stress curl approximate to the standard deviation of the annual-mean value seen in the CORE v.2b 19482007 winds (Fig. 1c). The anomalies are applied across the Indian Ocean Basin at every model time step (Fig. 1d). The drag coefficient and heat exchanges remain unaffected. Thus, only the dynamical effects of the modulated winds are considered. 
TABLE 1. Overview of the models used.

\begin{tabular}{lllc}
\hline \hline Configuration & \multicolumn{1}{c}{ Model } & Resolution & $\begin{array}{c}\text { Grid } \\
\text { spacing } \\
\text { at } 32^{\circ} \mathrm{S}(\mathrm{km})\end{array}$ \\
\hline ORCA05 & NEMO; global & $1 / 2^{\circ}$ & $\sim 45$ \\
AGIO & ROMS; basin scale & $1 / 4^{\circ}$ & $\sim 23$ \\
INALT01 & $\begin{array}{c}\text { NEMO; global } \\
\text { (nested) }\end{array}$ & $1 / 2^{\circ}\left(1 / 10^{\circ}\right)$ & $\sim 9$ \\
ARC112 & $\begin{array}{c}\text { ROMS; basin scale } \\
\text { (nested) }\end{array}$ & $1 / 4^{\circ}\left(1 / 12^{\circ}\right)$ & $\sim 7.5$ \\
& & & \\
\hline
\end{tabular}

\section{b. Models}

Previous studies linking the Agulhas Current and leakage in a realistic ocean use single simulations. To increase robustness, four separate model configurations are used in this study (summarized in Table 1). AGIO and ARC112 are based on the Regional Ocean Modeling System (ROMS) (Shchepetkin and McWilliams 2005). ORCA05 and INALT01 are constructed using the Nucleus for European Modelling of the Ocean (NEMO) platform. Both ROMS and NEMO have shown previous successes in appropriately representing the greater Agulhas system in the Southern Africa Experiment (SAfE) (Penven et al. 2006a) and AG01 configurations (Biastoch et al. 2009a), respectively. AGIO and ARC112 are discussed fully below. ORCA05 and INALT01 are described by Durgadoo et al. (2013).

\section{1) BASIN-SCALE MODELS}

ROMS is a split-explicit, free-surface, ocean-only model, discretized in coastline- and terrain-following curvilinear coordinates (Shchepetkin and McWilliams 2005). Higher-order numerics and a third-order, upstreambiased advection scheme preserve steep density gradients and reduce dispersion, enhancing the precision for a given resolution (Shchepetkin and McWilliams 2005). Subgrid-scale vertical mixing is governed by a nonlocal, $K$-profile parameterization (KPP) scheme (Large et al. 1994). The bottom boundary layer is determined by the KPP (Large et al. 1994), and a quadratic bottom drag is applied. Excess western boundary current (WBC) variability is selectively damped via a horizontal viscosity parameterization $A_{h}$ (Chassignet and Garraffo 2001; Penven et al. 2006b; Smagorinsky 1963), where $\Delta x / \Delta y$ are the zonal and meridional scales [(1)]:

$$
A_{h}=0.025 \times \frac{\Delta x \Delta y}{2} \times \mid \text { deformation tensor } \mid .
$$

Lateral viscosity is zero in the model interior, but increases in the sponge layer at the domain perimeter.
Here, prognostic variables are connected to the external conditions by an active radiation scheme (Marchesiello et al. 2001). The solution is nudged toward data where inflow occurs. To reduce spurious diapycnal mixing, the diffusive component of the Rotated, Split, Upstreambiased, 3rd Order (RSUP3) tracer advection scheme is rotated to follow geopotentials (Marchesiello et al. 2009). The parameterization of lateral friction alongside walls (free slip/no slip) is known to have a dramatic influence in $z$-coordinate models in the region (Quartly et al. 2013). This is not relevant in the case of $\sigma$-coordinate models, because the interaction with varying bottom topography does not involve lateral walls in this case.

AGIO is an extension of the SAfE configuration (Penven et al. 2006a), constructed using ROMSTOOLS (Penven et al. 2008). The $1 / 4^{\circ} \mathrm{C}$ grid domain spans the Indian Ocean Basin from $48.25^{\circ} \mathrm{S}$ to $7^{\circ} \mathrm{N}$ and $29^{\circ} \mathrm{W}$ to $115^{\circ} \mathrm{E}$ (Fig. 1d), capturing the mean zero line of wind stress curl (Fig. 1c) and subtropical front (STF). AGIO simulates the prominent features and mesoscale variability of the Indian Ocean and is considered eddy permitting at the latitude of the retroflection, where the grid scale is comparable to the first Rossby radius of deformation ( $\sim 30 \mathrm{~km}$; Chelton et al. 1998). The Indonesian archipelago is partially masked due to numerical instabilities in the sponge layer in the shelf seas. However, the Timor Sea remains open allowing for a realistic Indonesian Throughflow (ITF). To reduce pressure gradient errors, the bathymetry $h$, derived from $1^{\prime}$ General Bathymetric Chart of the Oceans (GEBCO; http://www.gebco.net), is bilinearly interpolated onto the grid and smoothed according to keep a slope parameter $r$ less than a value of $r_{0}=0.2$ [(2)] (Haidvogel and Beckmann 1999):

$$
r=\frac{\left(h_{+(1 / 2)}-h_{-(1 / 2)}\right)}{\left(h_{+(1 / 2)}+h_{-(1 / 2)}\right)} .
$$

The vertical resolution is described by $32 \sigma$-coordinate levels, which follow the bathymetry and are stretched toward the surface. Topography is smoothed toward the boundary condition bathymetry in the sponge layer. At the surface, AGIO is bulk forced (Fairall et al. 1996) with the CORE v.2b variables. No nudging occurs within the interior of the domain, and sea surface temperature and salinity can evolve freely. AGIO has a $200-\mathrm{km}$ sponge layer, in which viscosity linearly increases to $1000 \mathrm{~m}^{2} \mathrm{~s}^{-1}$. A Laplacian background diffusivity of $100 \mathrm{~m}^{2} \mathrm{~s}^{-1}$ is applied to the tracers.

ARC112 is identical to AGIO, but uses the Adaptive Grid Refinement in Fortran (AGRIF; Debreu et al. 2008) routine to enable a two-way, $1 / 12^{\circ}$ eddy-resolving 
TABLE 2. Summary of sensitivity experiments performed and the changes applied to the zonal trade wind stress (ztws). CNY refers to the CORE v.2b normal-year forcing fields and CI refers to the analogous 1948-2007 annually varying fields (Large and Yeager 2009). Unless otherwise specified, the ORCA05 monthly climatology (ORCA05r) is based on years 1-60 of the reference run. The suffixes i and $r$ indicate the interannual and climatological reference runs, respectively.

\begin{tabular}{|c|c|c|c|}
\hline Expt & Forcing/anomaly & Boundary conditions & Analysis period \\
\hline ORCA05r & CNY & Not applicable & $41-60$ \\
\hline ORCA05i & CI & Not applicable & 1992-2007 \\
\hline ORCAp40 & $\mathrm{CNY} 40 \%$ stronger ztws & Not applicable & $41-60$ \\
\hline ORCAp20 & CNY $20 \%$ stronger ztws & Not applicable & $41-60$ \\
\hline ORCAm 20 & CNY 20\% weaker ztws & Not applicable & $41-60$ \\
\hline ORCAm 40 & CNY $40 \%$ weaker ztws & Not applicable & $41-60$ \\
\hline AGIOr & $\mathrm{CNY}$ & ORCA05r & $41-60$ \\
\hline AGIOi & $\mathrm{CI}$ & ORCA05i 1948-2007 & 1992-2007 \\
\hline AGIOp40 & $\mathrm{CNY} 40 \%$ stronger ztws & ORCA05r & $41-60$ \\
\hline AGIOp20 & CNY $20 \%$ stronger ztws & ORCA05r & $41-60$ \\
\hline AGIOm20 & CNY $20 \%$ weaker ztws & ORCA05r & $41-60$ \\
\hline AGIOm40 & CNY $40 \%$ weaker ztws & ORCA05r & $41-60$ \\
\hline $\mathrm{AGBCr}$ & $\mathrm{CNY}$ & ORCA05r (41-60) & $21-40$ \\
\hline AGBCp40 & $\mathrm{CNY} 40 \%$ stronger ztws & ORCAp40r (41-60) & $21-40$ \\
\hline $\mathrm{AGBCm} 40$ & CNY $40 \%$ weaker ztws & ORCAm40r (41-60) & $21-40$ \\
\hline INALT01r & $\mathrm{CNY}$ & Not applicable & $41-60$ \\
\hline INALT01i & $\mathrm{CI}$ & Not applicable & $1992-2007$ \\
\hline INALT01p40 & $\mathrm{CNY} 40 \%$ stronger ztws & Not applicable & $41-60$ \\
\hline INALT01m40 & CNY $40 \%$ weaker ztws & Not applicable & $41-60$ \\
\hline ARC112r & $\mathrm{CNY}$ & ORCA05r & $41-60$ \\
\hline ARC112i & $\mathrm{CI}$ & ORCA05i 1948-2007 & 1992-2007 \\
\hline ARC112p40 & $\mathrm{CNY} 40 \%$ stronger ztws & ORCA05r & $41-60$ \\
\hline ARC112m40 & CNY $40 \%$ weaker ztws & ORCA05r & $41-60$ \\
\hline
\end{tabular}

nest over the retroflection region (Fig. 1d). Laplacian tracer diffusivity is zero within the nest. The two-way nest allows communication of the child ocean dynamics to the parent domain. Previous work suggests that source region eddies play a role in determining the timing of ring occlusion events (Penven et al. 2006b; Biastoch et al. 2008c). AGIO captures the mesoscale variability of the source regions, justifying the latitudinal extent of the ARC112 nest.

Initial and boundary conditions for AGIO and ARC112 are drawn from associated ORCA05 experiments (Table 2). All configurations undergo a primary, 30-yr spinup. In sensitivity experiments, anomalies, applied at every time step, are linearly ramped in over year 31 . After an anomaly spinup period (year 32-40), during which the experiments reach a steady state, the five daily outputs from years 41 to 60 are analyzed. Interannual boundary conditions (where interannual is indicated by a suffix $i$ ) are drawn from the ORCA05i run.

To test the sensitivity to the large-scale dynamics at the open boundaries, we perform a secondary set of experiments with variable boundary conditions. These are taken from the ORCA05r, ORCA05p40, and ORCA05m40 experiments, and are referred to as AGBC in Table 2 (where climatological is indicated by a suffix r). Here, the appropriate trade wind anomaly is applied at initialization, and the analysis is performed after a 20-yr spinup period.

\section{2) GlobAl Models}

ORCA05 is an established coarse-resolution, global, ocean-only model configuration that successfully reproduces the ocean circulation at the large scale (Biastoch et al. 2008a). It is based on version 3.1.1 of the NEMO code (Madec 2008) and includes the Louvain-la-Neuve Sea Ice Model, version 2 (LIM2) (Fichefet and Maqueda 1997). The tripolar grid with a Mercator grid south of $20^{\circ} \mathrm{N}$ has a nominal horizontal resolution of $1 / 2^{\circ}$. Vertically, $46 z$ levels are used, with partial cells in the bottom level to better represent the topography. A free-slip condition is used at the lateral boundaries.

INALT01 (Durgadoo et al. 2013) is an update of the AG01 configuration (Biastoch et al. 2009a). It consists of a parent model identical to ORCA05, but includes a regional nest, extending from $50^{\circ} \mathrm{S}$ to $8^{\circ} \mathrm{N}$ and $70^{\circ} \mathrm{W}$ to $70^{\circ} \mathrm{E}$ at $1 / 10^{\circ}$ horizontal resolution. Nest embedding is accomplished using the previously described AGRIF approach. INALT01 is eddy resolving, promoting 

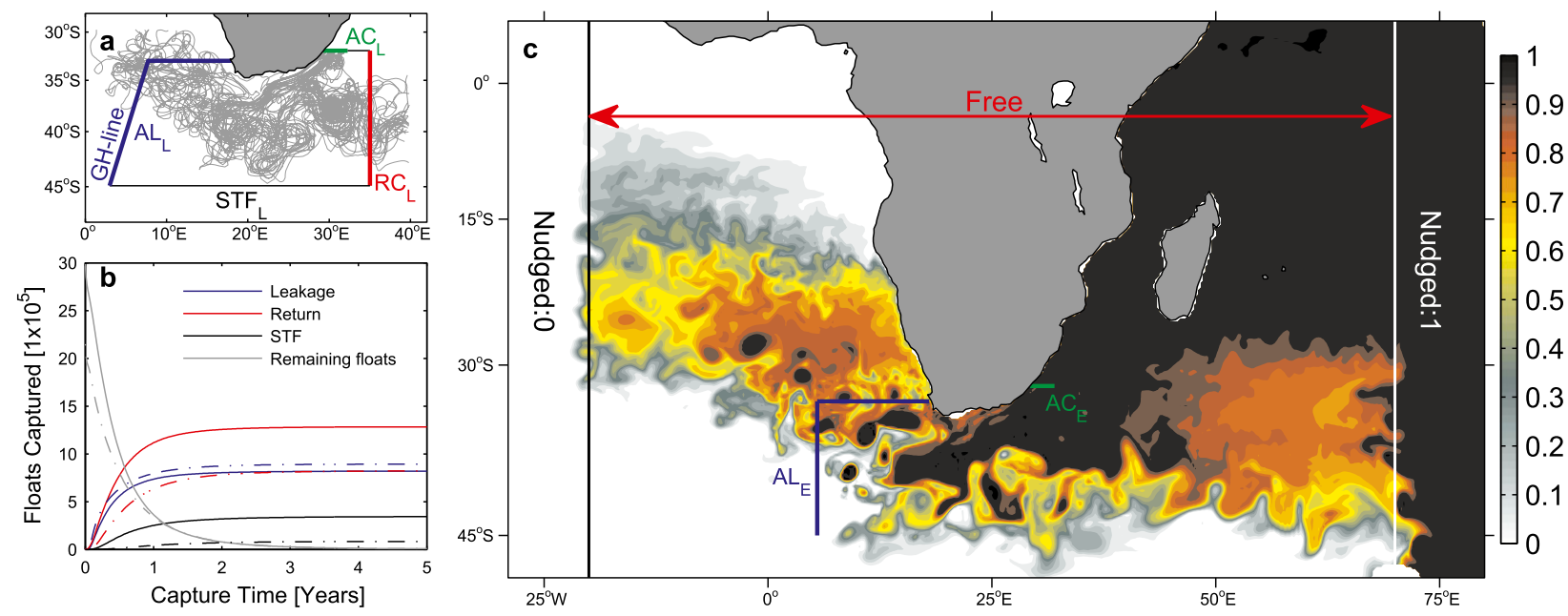

$25^{\circ} \mathrm{W}$

FIG. 2. (a) A schematic representation of the trajectories of particles released across the Agulhas Current. Lagrangian flux estimates for the Agulhas Current, leakage, return current, and subtropical front are measured across the $\mathrm{AC}_{L}, \mathrm{AL}_{L}, \mathrm{RC}_{L}$, and $\mathrm{STF}_{L}$ transects. The $\mathrm{AC}_{L}$ transect follows the path of the GH line (Swart et al. 2008). (b) The float capture times for 5-yr Lagrangian virtual float integrations in dashed lines for AGIOr and solid lines for ARC112r. (c) The five daily snapshots of the passive tracer $T_{p}$ field of ARC112r at $100 \mathrm{~m}$. The tracer field is free to evolve between $20^{\circ} \mathrm{W}$ and $70^{\circ} \mathrm{E}$, where it is nudged to 0 and 1 , respectively. Eulerian estimates for the Agulhas Current and leakage are calculated across the $\mathrm{AC}_{E}$ and $\mathrm{AL}_{E}$ sections.

a realistic rendering of the greater Agulhas system. As in the basin-scale models, surface fluxes for ORCA05 and INALT01 come from the CORE v.2b dataset.

\section{c. Agulhas leakage quantification}

Quantifying Agulhas leakage in the turbulent Cape Basin is challenging. Many attempts use a Lagrangian approach, seeding floats in the Agulhas Current and collecting across a nominal leakage section (Speich et al. 2001; Doglioli et al. 2006; Biastoch et al. 2008c, 2009b; van Sebille et al. 2009). By design, this defines leakage as the proportion of Agulhas Current waters exported into the Atlantic. This approach, while flexible, typically excludes diffusive processes, and offline calculations possibly sacrifice precision in turbulent regions.

Eulerian approaches face similar limitations. Typically, appropriate fluxes can only be sampled by imposing water mass criteria or by adjusting the extent of the sampling transect. This is a substantial problem in eddy-rich regions, and Eulerian estimates of flux across the GoodHope (GH) line (Swart et al. 2008) may substantially underestimate leakage (van Sebille et al. 2010b). To minimize ambiguity, we compare a Lagrangian approach with Eulerian leakage estimates derived from an online passive tracer that explicitly labels Indian Ocean water masses, removing the need for arbitrary criteria based on tracer properties or transect extent.

Lagrangian fluxes (indicated by a subscript $L$ ) are obtained from the ARIANE package (ARIANE v2.2.6; http://www.univ-brest.fr/lpo/ariane/) (Blanke and Raynaud 1997). Floats are dropped along an Agulhas Current section at $32^{\circ} \mathrm{S} \mathrm{AC}_{L}$, which stretches from the coast to the longitude of first recirculation. They are collected across the sections shown in Fig. 2a, with leakage $\mathrm{AL}_{L}$ measured across the $\mathrm{GH}$ line. The software automatically determines the number of floats released according to the current transport. Floats, each representing $0.1 \mathrm{~Sv}$, are dropped at five daily intervals across a single year and integrated for a further $4 \mathrm{yr}$, producing annual transport estimates for each section. After a 5-yr integration period, only $0.3 \%$ of floats remain within the control volume (Fig. 2b), defined as the area bounded by the transects in Fig. 2a.

Eulerian transports (indicated by a subscript $E$ ) are calculated from the passive tracer flux across the Agulhas Current $\mathrm{AC}_{E}$ and Cape Basin $\mathrm{AL}_{E}$ transects (Fig. 2c). The tracer is nudged to one to the east of $70^{\circ} \mathrm{E}$, indicating $100 \%$ Indian Ocean waters, and to zero west of $20^{\circ} \mathrm{W}$, representing Atlantic waters. Between these boundaries it is free to evolve through advection and diffusion. The tracer is initialized with the model and reaches equilibrium during the primary and anomaly spinup periods. Annual means are constructed from five daily fluxes.

\section{d. Vorticity balance}

To investigate retroflection behavior, we average $5 \mathrm{yr}$ of the ARC112 horizontal momentum equation tendency terms. Taking the curl, and integrating over depth $H$, we derive the vertical average of the equation for the vertical component of vorticity [(3)]: 


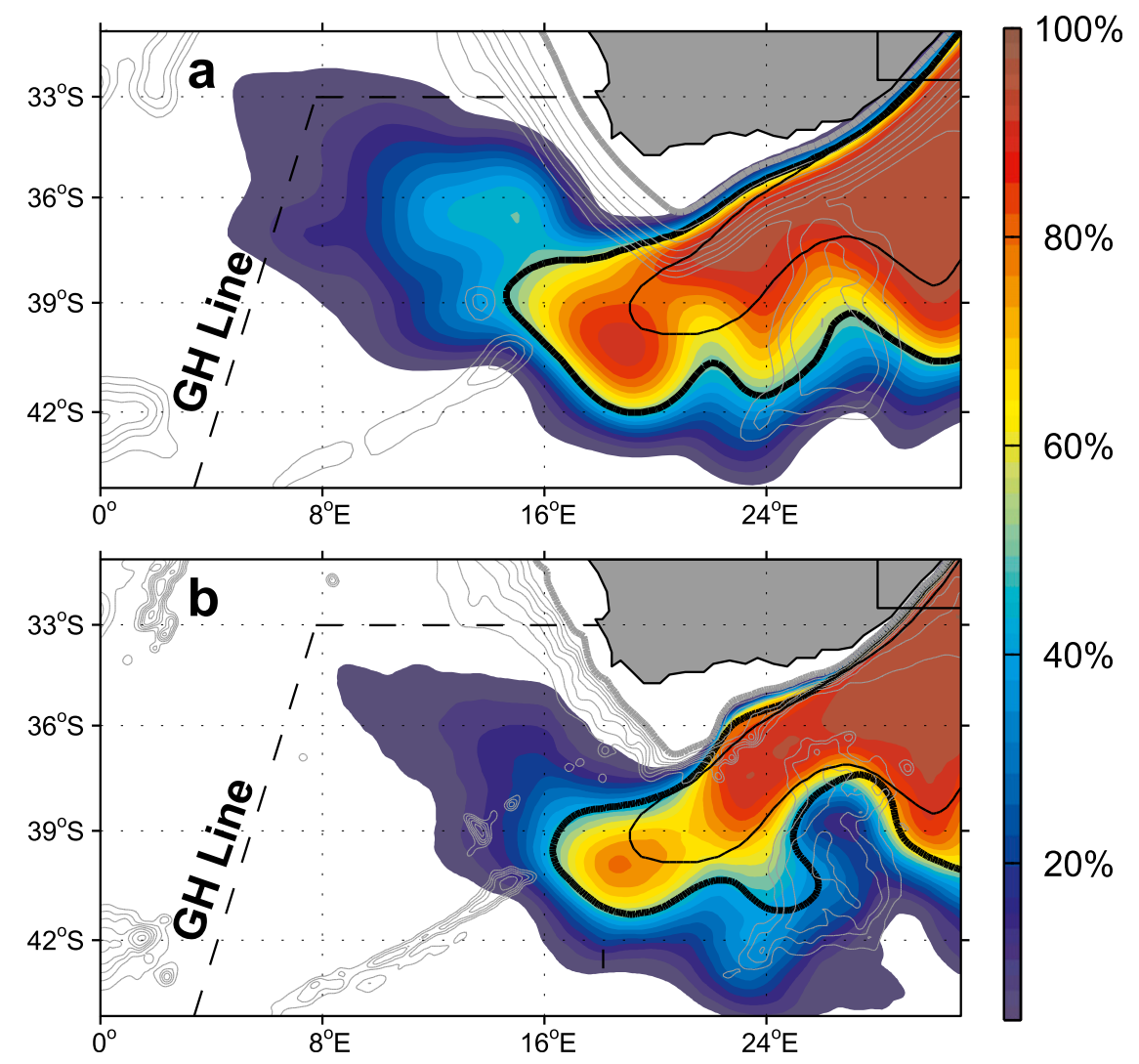

FIG. 3. Spatial extent of the retroflection position derived from the five daily SSHs for 19922007 (shading). Gray contours represent bathymetry at 500-m depth intervals, with the thick gray line following the 500-m isobath. The thick black contour shows the model retroflection path for (a) AGIOi and (b) ARC112i as derived from the mean SSH for the period. The thin line shows the mean retroflection path similarly derived for Archiving, Validation, and Interpretation of Satellite Oceanographic data (AVISO). The dashed transect shows the GH line.

$$
\begin{aligned}
0= & \underbrace{-\frac{1}{H} \int_{-H}^{0} \nabla_{h} \times \overline{\mathbf{u} \cdot \boldsymbol{\nabla} \mathbf{u}_{h}} d z}_{\boldsymbol{\nabla} \times \text { Advection(ADV) }} \underbrace{-\frac{1}{H} \int_{-H}^{0} \nabla_{h} \times \overline{f \mathbf{k} \times \mathbf{u}_{h}} d z}_{\boldsymbol{\nabla} \times \text { Coriolis }} \\
& \underbrace{+\frac{1}{H} \int_{-H}^{0} \nabla_{h} \times \overline{\frac{\partial}{\partial z} A_{v} \frac{\partial \mathbf{u}_{h}}{\partial z} d z}}_{\boldsymbol{\nabla} \times \text { Vertical Mixing(VMIX) }} \\
& \underbrace{+\frac{1}{H} \int_{-H}^{0} \nabla_{h} \times \overline{\nabla_{h} A_{h} \nabla_{h} \mathbf{u}_{h}} d z}_{\boldsymbol{\nabla} \times \text { Horizontal Mixing(HMIX) }} .
\end{aligned}
$$

Here, $\mathbf{u}\left(\mathbf{u}_{h}\right)$ is the (horizontal) velocity vector, $z$ and $w$ are the vertical coordinate and velocity, $f$ is the Coriolis parameter, $\mathbf{k}$ is the vertical unity vector, and $A_{v} / A_{h}$ are the vertical/horizontal turbulent mixing coefficients. Because of the vertical integral, VMIX is the difference between the wind stress curl and the vertical mixing flux at the bottom of the layer, which should be small at $1000 \mathrm{~m}$.
The $\nabla \times$ Coriolis term is separated into planetary advection $[\beta$ effect (BETAV)] [(4)] and vortex stretching (VSTR) $[(5)]$ contributions. For precision, we diagnose the latter from the difference between the $\beta$ effect and $\nabla \times$ Coriolis terms. The ADV and HMIX terms represents relative vorticity advection and viscous stress curl, respectively:

$$
\begin{gathered}
\frac{-\beta}{H} \int_{H}^{0} v d z \text { and } \\
\frac{f}{H} \int_{H}^{0} \frac{\partial w}{\partial z} d z
\end{gathered}
$$

\section{e. Deriving the retroflection position}

Retroflection extent is derived via a sea surface height ( $\mathrm{SSH}$ ) contour, tracked through the five daily fields [following Backeberg et al. (2012)]. The contour value is determined from the mean SSH spanning $30^{\circ}-32.5^{\circ} \mathrm{S}$, $28^{\circ}-32.5^{\circ} \mathrm{E}$, capturing the upstream Agulhas Current where the flow is less turbulent (Fig. 3). To capture the 
inshore current edge, the mean value is considered where $200<h<1500 \mathrm{~m}$. The westernmost contour value is taken as the maximum loop extent. Retroflection positions are spatially binned into $1 / 2^{\circ}$ longitudinal boxes, producing a zonal probability density function for each experiment.

\section{f. Evaluation of models}

The mean SSH for 1992-2007 suggests that all interannual simulations exhibit a large-scale circulation consistent with altimetry (Fig. 4). The Agulhas Current draws waters from the Southeast Madagascar Current (SEMC) and Mozambique Channel (MZC), with measured transports of 20-30 (Donohue and Toole 2003; Nauw et al. 2008) and 16.7 Sv (Ridderinkhof and de Ruijter 2003; van der Werf et al. 2010), respectively. Simulated SEMC transport compares well with observations, while MZC fluxes are higher (Table 3). Farther downstream, simulated Agulhas Current transports of $65.5-76.9 \mathrm{~Sv}$ are broadly consistent with the $69.7 \mathrm{~Sv}$ observed at $32^{\circ} \mathrm{S}$ (Bryden et al. 2005) [updated to 78.6 Sv by Biastoch et al. (2009a)]. Transports in the ARC112r and ARC112i are similar, though less variable in the former due to a shorter sampling period and lack of interannual variability.

Increasing the spatial resolution has a clear effect on the Agulhas leakage magnitude (Table 3). At lower resolution, ORCA05i and AGIOi record 25.8 and $32.7 \mathrm{~Sv}$, respectively. Consequently, AGIOi deviates from observations in the Agulhas Return Current, which is weaker and less coherent than observed (Boebel et al. 2003) (Fig. 4). In comparison, INALT01 ${ }_{i}$ and ARC112 ${ }_{i}$ record leakage values of 15.9 and $18.9 \mathrm{~Sv}$, closer to the $15 \mathrm{~Sv}$ observed from drifter paths (Richardson 2007).

Eddy kinetic energy (EKE) patterns (Fig. 4) suggest that AGIOi, ARC112i, and INALT01i capture the mesoscale variability inherent to the Agulhas source regions. High EKE values in the MZC reflect the appropriate formation of anticyclonic eddies, a consequence of the presence of Madagascar (Penven et al. 2006b; Ridderinkhof and de Ruijter 2003). South of Madagascar, EKE is lower than observed, suggesting that eddy formation in the SEMC (de Ruijter et al. 2004; Siedler et al. 2009) is perhaps underrepresented. Because of the lower resolution, ORCA05, shows reduced EKE throughout, with MZC flow represented by a weak western boundary current as opposed to eddies.

At the retroflection, the eddying configurations show a spatial EKE distribution close to that observed. Agulhas rings appropriately spread across the Atlantic. The return current EKE in $\mathrm{ARC112}_{i}$ shows an improvement over that of AGIOi. Inappropriate numerical choices can result in an unrealistic eddy train at the western boundary or spurious upstream recirculation, expressed as high
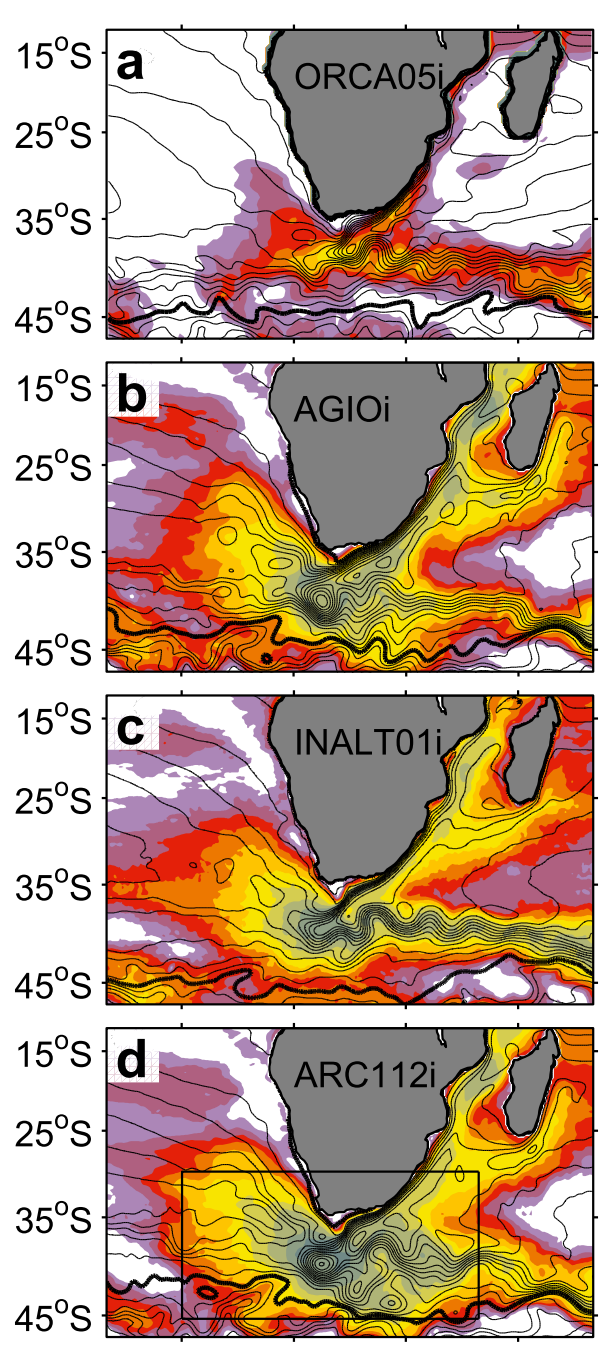

1000

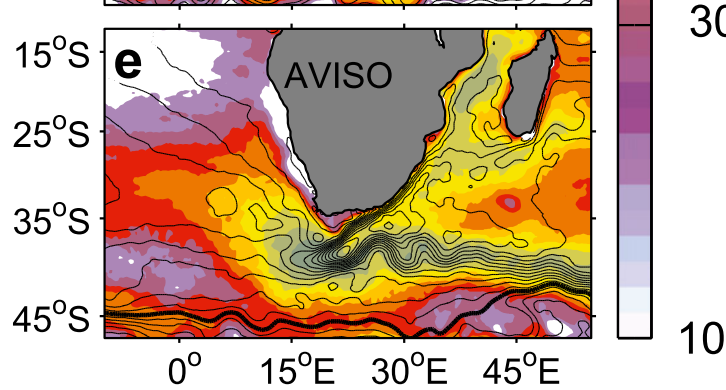

30

FIG. 4. EKE for 1992-2007 from (a) ORCA05i, (b) AGIOi, (c) INALT01i, (d) ARC112i, and (e) AVISO. EKE is calculated from geostrophic velocities derived from the SSH. Contours show $10-\mathrm{cm}$ delineations of mean $\mathrm{SSH}$ for this period.

EKE along the South African coast and upstream of the retroflection, respectively. Neither pattern is in evidence here. Because of the objective mapping of the along-track data, the observed background signal is stronger and appears more smoothed.

Because of the low viscosity (see, e.g., HMIX in Fig. 7, described in greater detail below) Ekman numbers in 
TABLE 3. Annual mean and transports (Sv) for the interannual (suffix i; 1948-2007) and climatological (suffix r, year 41-60) reference simulations. Annual std dev are given for the models. To match observations, the mean Agulhas Current $\mathrm{AC}_{B}$ transport is calculated for the 1995-2004 period, with five daily std dev. Transports are measured in the South East Madagascar Current $\mathrm{SEMC}_{D}$, the Mozambique Channel $\mathrm{MZC}_{R}$, and Agulhas Return Current $\mathrm{RC}_{L} \cdot \mathrm{AC}_{B}, \mathrm{SEMC}_{D}$, and $\mathrm{MZC}_{R}$ transports are calculated across transects extracted from the references provided (Fig. 1d). For AGIOi, ARC112r, and ARC112r southwestward transport for $\mathrm{AC}_{B}$ is calculated through a staircase section from original model velocities extracted using Physical Analysis of Gridded Ocean data (PAGO) (http://www.whoi. edu/science/PO/pago). Agulhas leakage is quantified using Lagrangian $\mathrm{AL}_{L}$ and Eulerian $\mathrm{AL}_{E}$ approaches (Fig. 2). The subscripts $\mathrm{R} / \mathrm{D} / \mathrm{B}$ on MAC/SEMC/AC are used as the transport in these columns are calculated in a manner consistent with the references given (Ridderinkhof/Donohue/Bryden). Subscripts L and E denote transport derived from lagrangian and eulerian transport calculations, respectively.

\begin{tabular}{|c|c|c|c|c|c|c|}
\hline Configuration & $\mathrm{MZC}_{R}$ & $\mathrm{SEMC}_{D}$ & $\mathrm{AC}_{B}$ & $\mathrm{AL}_{L}$ & $\mathrm{AL}_{E}$ & $\mathrm{RTN}_{L}$ \\
\hline ORCA05i & $26.0 \pm 3.2$ & $22.8 \pm 2.4$ & $65.5 \pm 3.8$ & $25.8 \pm 4.5$ & - & $37.0 \pm 5.7$ \\
\hline AGIOi & $26.9 \pm 3.3$ & $29.2 \pm 5.2$ & $76.9 \pm 19.9$ & $32.7 \pm 3.5$ & $27.6 \pm 2.8$ & $30.5 \pm 4.8$ \\
\hline INALT01i & $18.8 \pm 8.8$ & $22.9 \pm 5.6$ & $67.9 \pm 16.7$ & $15.9 \pm 3.7$ & - & $43.0 \pm 4.7$ \\
\hline ARC112i & $25.3 \pm 3.3$ & $28.5 \pm 4.1$ & $76.1 \pm 20.4$ & $18.9 \pm 3.2$ & $18.8 \pm 2.7$ & $31.1 \pm 4.6$ \\
\hline ARC112r & $25.0 \pm 0.8$ & $24.7 \pm 2.3$ & $76.2 \pm 24.7$ & $19.8 \pm 1.6$ & $19.2 \pm 1.5$ & $32 \pm 1.5$ \\
\hline OBSERVED & $16.7^{\mathrm{a}}$ & $\begin{array}{l}20.0^{\mathrm{b}} \\
30.0^{\mathrm{c}}\end{array}$ & $\begin{array}{l}69.7 \pm 21.5^{\mathrm{d}} \\
78.6 \pm 19.7^{\mathrm{e}}\end{array}$ & $15.0^{\mathrm{f}}$ & - & $44.0^{\mathrm{g}}$ \\
\hline
\end{tabular}

${ }^{a}$ Ridderinkhof and de Ruijter (2003) and van der Werf et al. (2010).

${ }^{\mathrm{b}}$ Donohue and Toole (2003).

${ }^{\mathrm{c}}$ Nauw et al. (2008).

${ }^{\mathrm{d}}$ Bryden et al. (2005).

${ }^{\mathrm{e}}$ Biastoch et al. (2009a).

${ }^{\mathrm{f}}$ Richardson (2007).

${ }^{\mathrm{g}}$ Boebel et al. (2003).

AGIOi and ARC112i are small $\left(1.6 \times 10^{-8}\right.$ and $7.7 \times$ $\left.10^{-9}\right)$, suggesting inertially governed retroflections (Dijkstra and de Ruijter 2001). However, bathymetry smoothing in AGIO reduces the protrusion of the Agulhas Bank, allowing the current to overshoot the shelf in a near-zonal direction (Fig. 3). Similar behavior is seen in experiments with an excised Agulhas Bank (Speich et al. 2006). Consequently, while both models display a more westward retroflection than observed, the retroflection in $\mathrm{AGIO}_{i}$ crosses the $\mathrm{GH}$ line $7 \%$ of the time.

During Lagrangian quantification, ARIANE automatically removes floats counted at the $\mathrm{GH}$ line as leakage. Where the retroflection extends farther westward than this, floats cannot recirculate back into the Indian Ocean. Eulerian fluxes do not suffer from this limitation, which results in a discrepancy between Lagrangian $(32.7 \mathrm{~Sv})$ and Eulerian $(26.5 \mathrm{~Sv})$ leakage estimates for AGIOi. In ARC112i, the retroflection never crosses the $\mathrm{GH}$ line, and the two methods reach agreement at $\sim 19 \mathrm{~Sv}$.

\section{Results}

\section{a. Basin-scale circulation changes}

The large-scale circulation shows well-established tropical and subtropical gyres in all four models, with barotropic transports of -20 and $80 \mathrm{~Sv}$ in $\mathrm{ARC} 112_{r}$ (Fig. 5a). Away from the western boundary, gyre transports compare well with theoretical values from Sverdrup theory. Discrepancies between barotropic and Sverdrup transports are attributed to the influx of $\sim 20 \mathrm{~Sv}$ via the ITF, evident in the streamlines entering the domain north of Australia. The simulated ITF is slightly stronger than the 16-Sv one observed (Godfrey 1989).

In all models, transport contributions from the source regions reach a confluence in the northern Agulhas Current, forming a coherent western boundary flow at $26^{\circ} \mathrm{S}$. Barotropic transport contours show most of this flow reaching the retroflection. ARC112r has slightly increased in upstream recirculation compared to its interannual counterpart (Fig. 4d). This is not evident in the other models. The incoherent transport path between the South Atlantic basin and Indian Ocean Basin reflects the expression of Agulhas leakage via rings. The southern branch of the supergyre is clear in the (arbitrary) zero-transport line spanning the domain. South of this line, eastward transport indicates the Antarctic Circumpolar Current (ACC).

Between the equator and $15^{\circ} \mathrm{S}$, strengthening trade winds produce a more negative wind stress curl value (Fig. 1c). The associated increase in cyclonic vorticity input produces a stronger tropical gyre in all models, evident in the barotropic transports of ARC112 (Figs. 5b,c). Augmented circulation is expressed in faster flow at $100 \mathrm{~m}$ in the South Equatorial Current (SEC), Northeast Madagascar Current (NEMC), East African Coastal Current (EACC), and South Equatorial Counter Current 


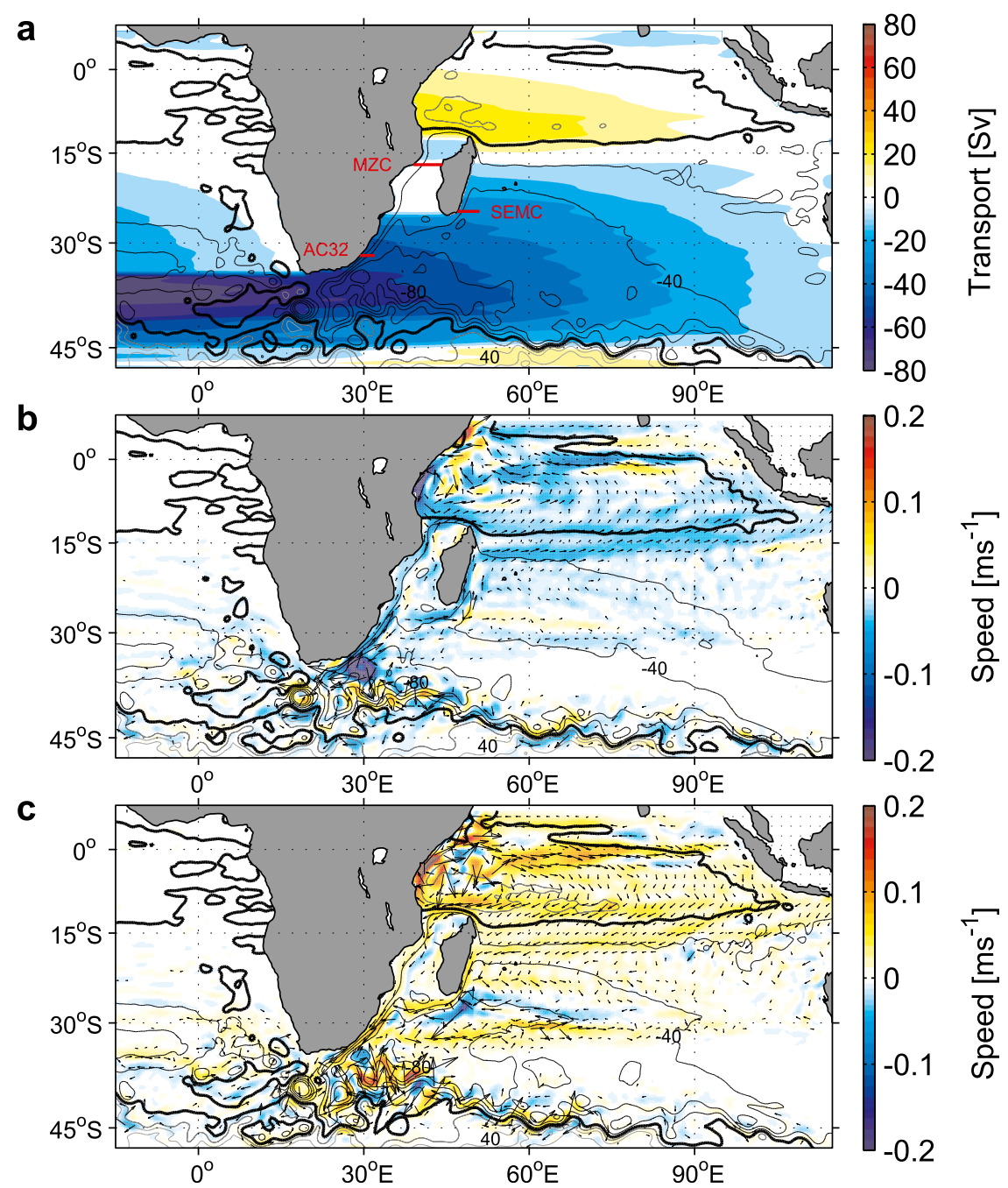

FIG. 5. (a) The annual-mean barotropic transport for the $\mathrm{ARC} 112_{r}$ simulation in black contours. Shading shows the Sverdrup transport, derived from the wind field for the same simulation, with $\psi=0$ at the eastern boundary. Barotropic transports across the black transects are shown in Table 4. Contours showing the mean barotropic transport function overlaid on anomalies in speed at $100 \mathrm{~m}$, shown in color and vector, for (b) ARC112m40 and (c) ARC112p40, respectively.

(SECC) (Fig. 5c). A symmetrical response is seen when the trade winds weaken (Fig. 5b).

South of $15^{\circ} \mathrm{S}$, increased positive wind stress curl drives intensification in the anticyclonic transport of the subtropical gyre in all four configurations (Fig. 5b). The converse is seen in Fig. 5c. Strong circulation anomalies, associated with changes in the SEMC, arise to the east and south of Madagascar, between $26^{\circ}$ and $30^{\circ} \mathrm{S}$, where changes in the wind stress curl are most pronounced and changes in the input of anticyclonic vorticity are greatest (Fig. 1c). Anomalies in gyre transport become less intense south of $32.5^{\circ} \mathrm{S}$ as imposed changes in wind stress curl are confined to latitudes north of this.
At the southern tip of Madagascar, the SEMC extends in two modes (Siedler et al. 2009). The southern mode retroflects, connecting the SEMC to the transient, eastward-flowing, South Indian Counter Current (SICC) through eddies, ejecting the remainder westward (Siedler et al. 2006, 2009). Under intensified trade winds, increased transport and speed between Madagascar and the African coast at $27^{\circ} \mathrm{S}$ (Fig. 5c) suggest an increase in the respective proportion of ejected waters in all configurations. Consequently, contributions to the SICC decrease, producing negative speed and transport anomalies offshore of Madagascar at $27^{\circ} \mathrm{S}$. 
TABLE 4. Mean barotropic transports (Sv) for the source regions for ARC112 and INALT01 sensitivity experiments. Extraction transects are shown in Fig. 5. AC32 refers to the transport of the Agulhas Current at $32^{\circ} \mathrm{S}$.

\begin{tabular}{|c|c|c|c|c|c|c|}
\hline Configuration & MZC & $\Delta \mathrm{MZC}$ & SEMC & $\Delta \mathrm{SEMC}$ & AC32 & $\triangle \mathrm{AC} 32$ \\
\hline ARC112m40 & 22.7 & -2.5 & 18.2 & -6.5 & 61.7 & -8 \\
\hline ARC112r & 25.2 & - & 24.7 & - & 69.7 & - \\
\hline ARC112p40 & 27.4 & +2.2 & 30.1 & +5.4 & 79.0 & 9.3 \\
\hline INALT01m40 & 17.0 & -1.8 & 11.2 & -7.5 & 65.8 & -2.8 \\
\hline INALT01r & 18.8 & - & 18.7 & - & 68.6 & - \\
\hline INALT01p40 & 20.8 & +2.0 & 23.6 & +4.9 & 71.5 & 2.9 \\
\hline
\end{tabular}

In all models, source region transports increase with subtropical gyre strength (Table 4). The SEMC shows a near-linear response to changes in wind stress curl, consistent with estimates derived from Sverdrup theory (Fig. 5). Linear circulation changes in the MZC are less pronounced due to the bifurcation of the NEMC at the African coast, the mesoscale variability of the flow, and the smaller change in wind stress curl at $13^{\circ} \mathrm{S}$ (compared to $27^{\circ} \mathrm{S}$ ).

Throughout, stronger source region transports are reflected at the western boundary, where transport and speed increase with increased wind stress curl (Figs. 5b,c; Table 4). This response is discussed later in section 3c. In all simulations, a strengthening Agulhas Return Current accompanied stronger WBC flow (Fig. $5 \mathrm{c})$. However, the anomaly signal becomes convoluted downstream as the return current sheds transport (Boebel et al. 2003). None of the sensitivity experiments show any changes in return current speed or transport east of $85^{\circ} \mathrm{E}$, suggesting that adjustment to the wind changes predominantly occurs within the Indian Ocean Basin.

The barotropic transport of the southeast Atlantic Ocean remains unchanged in ARC112 $r$ and INALT01. Changes in current speed are minimal outside of the Cape Basin. There is no significant change in either the barotropic transport or speed of the ACC in any simulation (Fig. 5).

\section{b. Mesoscale variability}

Excepting ORCA05, the SEMC, MZC, and retroflection regions are characterized by pronounced mesoscale variability in all models (Fig. 4). Anomalies in mean kinetic energy (MKE) and EKE for the ARC112 sensitivity experiments are shown in Fig. 6 and Table 5 . In general, these patterns are echoed in INALT01.

Agulhas source regions show a near-linear transport response to increased wind stress curl in all models (Table 4). North of Madagascar, this translates to a symmetrical response in MKE, with increased transport associated with large positive anomalies in the NEMC (Fig. 6a). As a consequence of the predominantly eddy-driven flow, MKE in the MZC remains small in ARC112. Higher MKE in INALT01 (not shown), particularly under intensified winds, may be attributable to the freeslip conditions in the channel for this model (Quartly et al. 2013). Increased (decreased) variability in the northern channel and Comoros Gyre occurs concurrently with stronger (weaker) winds in both eddy-resolving configurations, due to the increased (decreased) barotropic instability associated with modified SEC transport (Biastoch and Krauss 1999; Backeberg and Reason 2010). In contrast, the southern channel and northern Agulhas show negative EKE anomalies when winds intensify, possibly attributable to the eddies ejected from the SEMC (Quartly and Srokosz 2004), or increased incorporation of variability into the mean Agulhas. The patterns expressed under intensified winds are consistent with those observed by Backeberg et al. (2012).

East of Madagascar, the SEMC shows strongly positive (negative) MKE anomalies at stronger (weaker) winds, ubiquitous across models. Offshore, anomalies of opposite polarity at $28^{\circ} \mathrm{S}$ are consistent with reduced (increased) transport changes in the SICC, a consequence of the SEMC circulation changes noted previously. However, the net effect in SEMC MKE is minimal (Table 5). Weaker SEMC retroflections are associated with increased eddy production, evident in positive EKE anomalies between Madagascar and the African coast, and reduced eddy variability in the SICC (Table 5).

Flow in the stable northern Agulhas, north of $32^{\circ} \mathrm{S}$, is more confined to the mean under intensified winds, evident in the positive MKE and negative EKE anomalies seen here. Farther south, where the flow becomes more turbulent, large positive anomalies suggest a more variable Agulhas enters the retroflection region at increased transport (Figs. 6a,c). In the case of weaker winds, the offshore Agulhas shows a pronounced decrease in MKE and EKE, consistent with the upstream recirculation shown in Fig. $5 b$.

The retroflection and Cape Basin show large changes in EKE and MKE in all models. Positive anomalies are associated with stronger trade winds, which suggest increases in retroflection turbulence and potential changes 

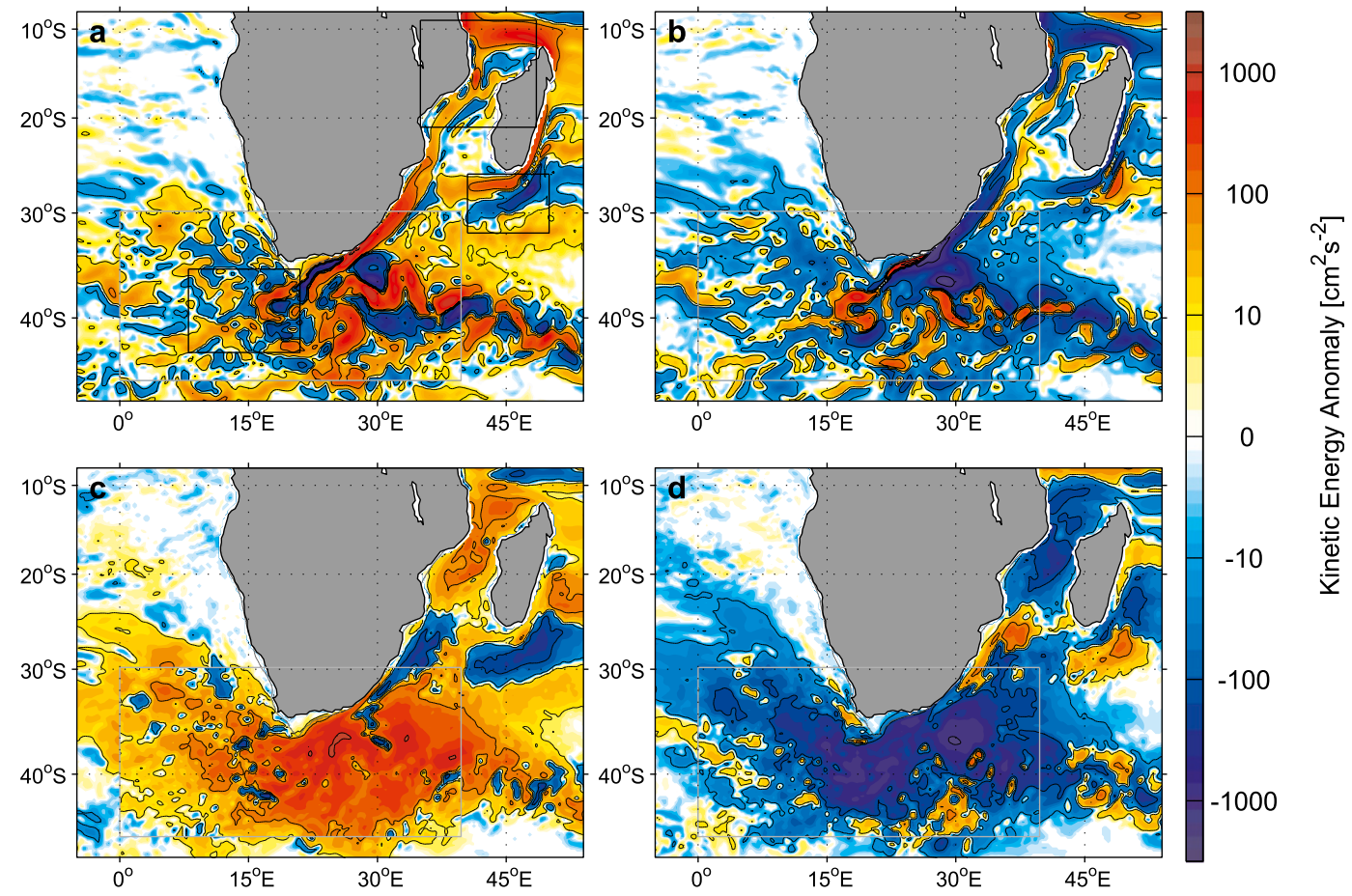

FIG. 6. MKE anomalies for (a) ARC112p40 and (b) ARC112m40. EKE anomalies for (c) ARC112p40 and (d) ARC112m40. Black contours follow the $\pm 10,100$, and $1000 \mathrm{~cm}^{2} \mathrm{~s}^{-2}$ isolines. The light gray box delineates the ARC112 nest boundary. Area means for the black boxes spanning the MZC and SEMC, and retroflection regions in (a) are given in Table 5 .

in Agulhas ring formation. Positive anomalies in Agulhas Current MKE and retroflection EKE are reflected in the return current, consistent with the changes in speed and transport we noted previously in INALT01 and ARC112 (Fig. 5c). Despite this, South Atlantic anomalies are low across all models $\left[O(10) \mathrm{cm}^{2} \mathrm{~s}^{-2}\right]$ outside of the Cape Basin.

\section{c. Western boundary responses}

Linear Sverdrup theory implies that changes in wind stress curl modulate vorticity input and should be reflected in WBC transport. Figure 7 compares WBC transports derived from the Sverdrup relationship, with barotropic transports from AGIO and ARC112. As expected, Sverdrup transport increases with latitude between $20^{\circ}$ and $35^{\circ} \mathrm{S}$ (Fig. 7a), a consequence of increasing wind stress curl. Applying the $\pm 40 \%$ anomalies produces a corresponding change in implied poleward transport north of $32.5^{\circ} \mathrm{S}$. South of this, where no anomaly is applied, transport returns to the reference value. East of Madagascar, barotropic transports in AGIO and ARC112 (Figs. 7b,c, respectively) follow a similar pattern, showing an accumulation of poleward volume flux. Bar plots (Fig. 7d) show the relative contributions of the vorticity term, vertically integrated over the top $1000 \mathrm{~m}$ and zonally integrated across the Indian Ocean. East of Madagascar (equatorward of $26^{\circ} \mathrm{S}$ ), the BETAV and VMIX bars almost balance in all experiments, indicating a Sverdrup balance between wind stress curl and planetary vorticity. Low horizontal viscosity is reflected in the small HMIX values throughout.

South of Madagascar $\left(26^{\circ} \mathrm{S}\right)$, advection of ITF waters through the MZC disrupts the Sverdrup balance. Advection is compensated by vortex stretching between $28^{\circ}$ and $30^{\circ} \mathrm{S}$. However, barotropic anomalies of $\pm 10 \mathrm{~Sv}$ in AGIO and ARC112 are low compared with $\pm 17 \mathrm{~Sv}$ dictated by theory, attributable to eddy-mean interaction at the boundary (Biastoch et al. 2009a). Consequently, although barotropic transport shows a near-linear relationship with wind stress curl, transport diverges from the theoretical estimates farther south.

TABLE 5. Kinetic energy values $\left(\mathrm{cm}^{2} \mathrm{~s}^{-2}\right)$ calculated from the five daily ARC112 SSH fields from across the retroflection (RETRO), MZC, and SEMC boxes shown in Fig. 9. Observed values for EKE and MKE are calculated from 7-day AVISO altimetry products for the 1992-2007 period.

\begin{tabular}{lccc}
\hline Configuration & MZC $_{\text {EKE/MKE }}$ & SEMC $_{\text {EKE/MKE }}$ & RETRO $_{\text {EKE/MKE }}$ \\
\hline ARC112m40 & $561 / 398$ & $249 / 100$ & $1177 / 330$ \\
ARC112r & $616 / 493$ & $234 / 114$ & $1391 / 333$ \\
ARC112p40 & $699 / 503$ & $191 / 100$ & $1541 / 344$ \\
OBSERVED & $521 / 207$ & $421 / 64$ & $928 / 175$ \\
\hline
\end{tabular}




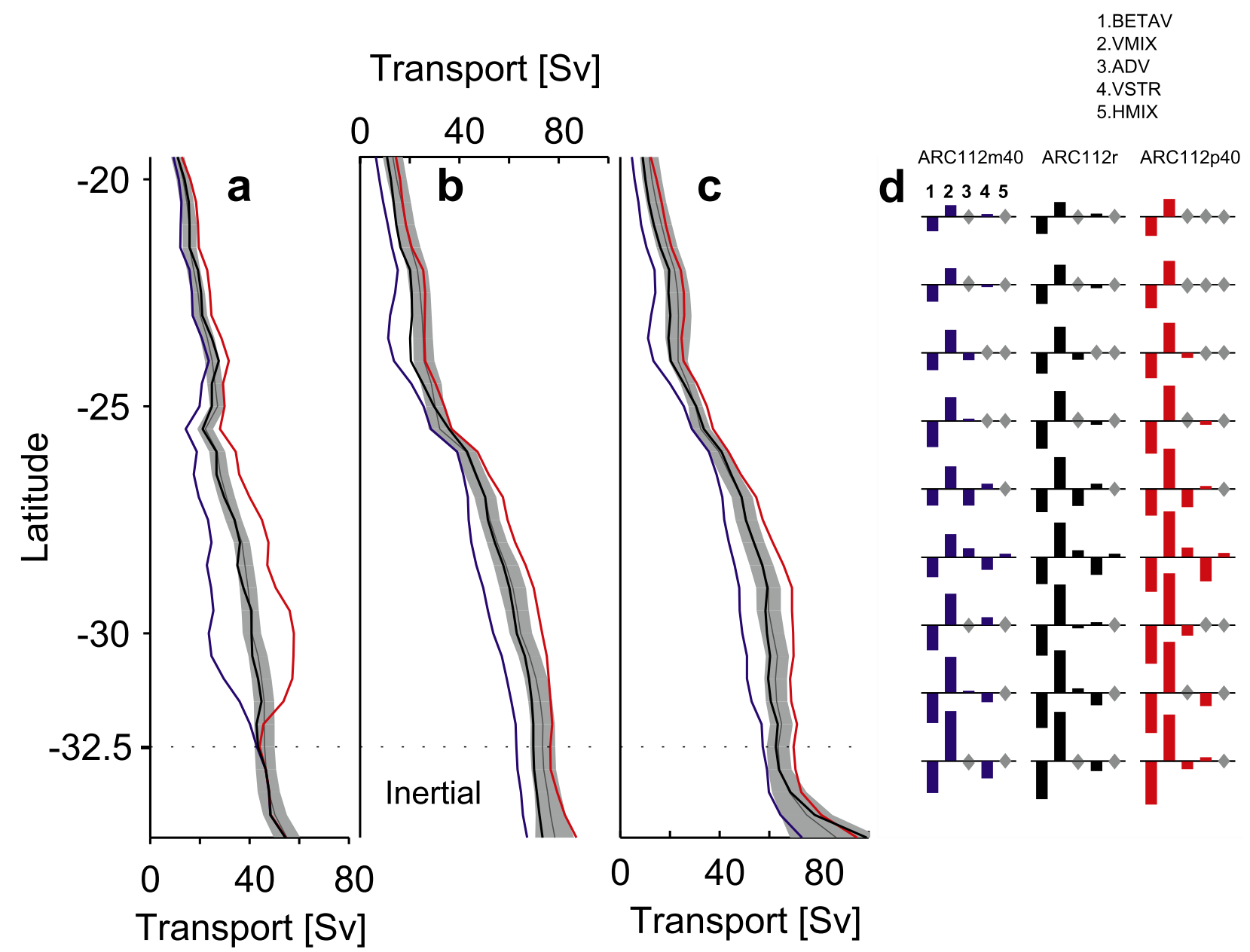

FIG. 7. Changes in western boundary transport with lat derived from (a) the Sverdrup relation, and barotropic transport functions for (b) AGIO and (c) ARC112. Blue, black, and red lines represent the $-40 \%$, reference, and $+40 \%$ experiments, respectively. Barotropic transport values are calculated as the difference between the max streamfunction value within $250 \mathrm{~km}$ of the $500-\mathrm{m}$ isobath and the coastal value. The gray lines show the analogous quantities from the 1948-2007 interannual experiments, with the gray envelope showing the annual std dev. (d) Relative importance of the zonally and vertically integrated vorticity balance terms are shown in the bars for selected lat. (from left to right) BETAV, VMIX, ADV, VSTR, and HMIX. Bar colors correspond to the associated sensitivity experiment (blue, ARC112m40; black, ARC112 ; and red, ARC112p40). Gray diamonds indicate near-zero terms.

Because of inertia, barotropic transport anomalies persist poleward south of $32^{\circ} \mathrm{S}$ (Figs. $7 \mathrm{~b}, \mathrm{c}$ ). This is reflected in the increased BETAV term, which is balanced by vortex stretching (and advection in ARC112p40), rather than through VMIX, which remains at a near-fixed value. At $34^{\circ} \mathrm{S}, \mathrm{ARC} 112 \mathrm{p} 40$ and $\mathrm{ARC} 112_{r}$ transports converge, suggesting a degree of readjustment. In contrast, transport at weaker winds is greatly reduced. In AGIO, where upstream recirculation occurs less frequently, the values do not converge.

\section{d. Agulhas leakage sensitivity}

Annual-mean Lagrangian transport estimates for the Agulhas Current and leakage are summarized in Fig. 8a. Agulhas Current transport increases near linearly with wind stress. ORCA05 and INALT01 show a \pm 30 -Sv change. ARC112 and AGIO show a larger \pm 8 -Sv change that is reflected in the Eulerian transports (Fig. 8b). As Eulerian estimates capture equator- and poleward velocity components, the Agulhas Undercurrent is sampled, producing lower transport values.

While the current response is consistent across the models, the leakage response is not (Figs. 8a,b). At lower resolution, ORCA05 shows an anticorrelation between the two transports (Fig. 8a). Conversely, leakage in AGIO increases with wind stress (Figs. 8a,b; blue triangles). In both cases, differences between mean leakage values exceed the reference annual-mean standard deviation (Table 6), suggesting that internal variability cannot account for the interexperiment changes. 

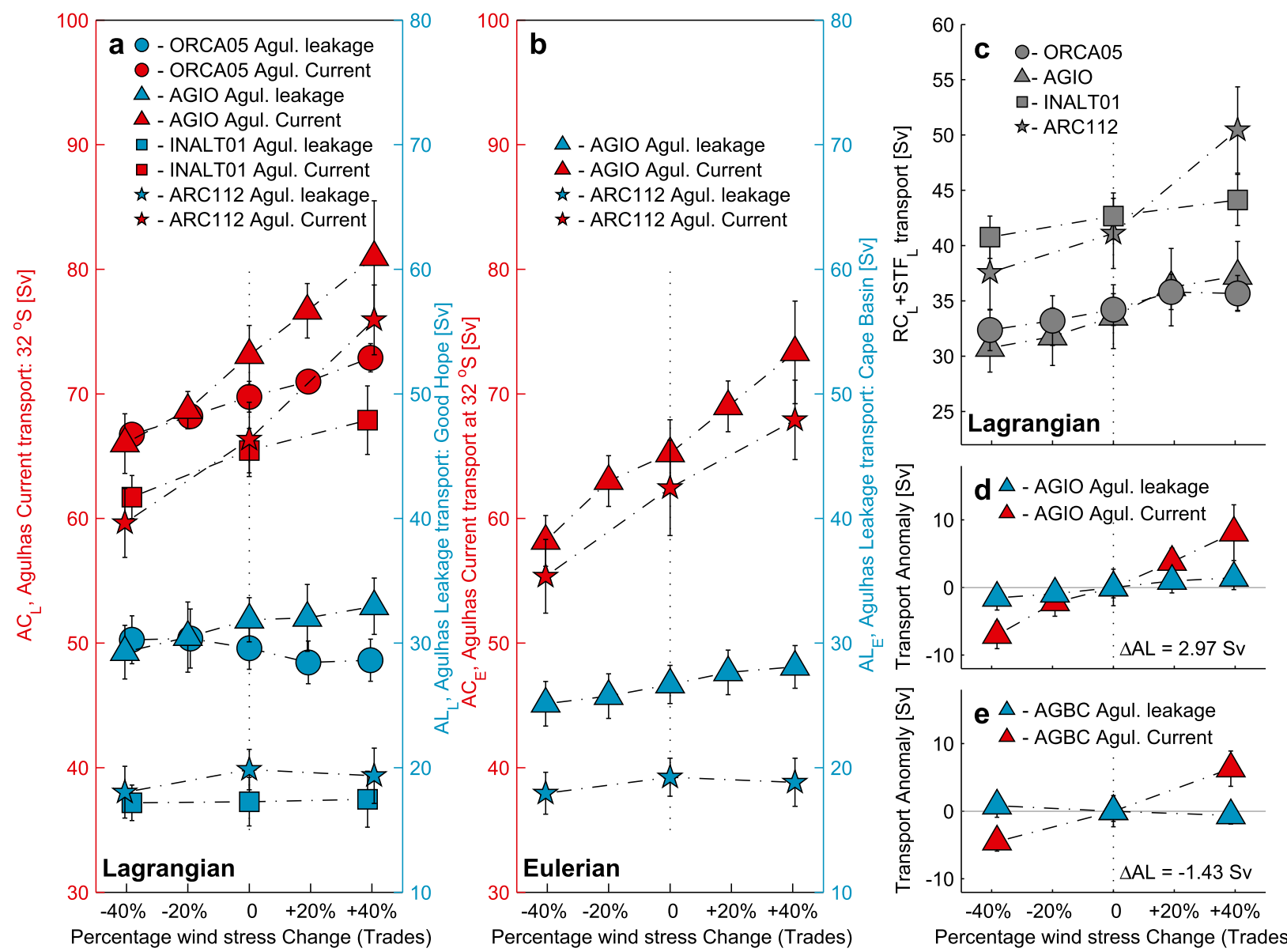

FIG. 8. Changes in Agulhas Current transport and leakage magnitude with trade wind stress. Annual-mean estimates derived from (a) Lagrangian flux (all models) and (b) Eulerian passive tracer flux (for basin-scale configurations). Blue and red values correspond to the Agulhas leakage and Agulhas Current, respectively. (c) The sum of the Lagrangian transport estimates for the Agulhas Return Current and across the subtropical front. (d),(e) Comparison of the Eulerian transport anomalies for the Agulhas Current and leakage for the AGIO sensitivity experiments with the transport anomalies from the variable boundary AGBC experiments (described in Table 2). The delta values show the change on Agulhas leakage for each series (see Table 6).

The correlation between current and leakage seen in AGIO is reflected in the passive tracer fluxes. The offset in values is ascribed to the westward retroflection position, discussed previously.
As the resolution increases, the leakage changes decrease and model behavior converges (Table 6). In ARC112 and INALT01, the models that most closely approximate observations (Fig. 4; Table 3), changes in

TABLE 6. Summary of the changes in Agulhas Current $\Delta \mathrm{AC}$ and Agulhas leakage $\Delta \mathrm{AL}$ across the sensitivity experiments. Subscripts $L$ and $E$ refer to the Lagrangian and Eulerian flux estimates shown in Fig. 7. Std dev are given for the reference (ref) experiment; boldface values indicate where this exceeds $\Delta \mathrm{AL}$ (no significant change). The right-hand column shows the sensitivity of the leakage to changes in the Agulhas Current transport.

\begin{tabular}{|c|c|c|c|c|c|c|}
\hline Configuration & Resolution & $\Delta \mathrm{AC}(\mathrm{Sv})$ & Std dev $\mathrm{AC}_{\mathrm{ref}}(\mathrm{Sv})$ & $\Delta \mathrm{AL}(\mathrm{Sv})$ & Std dev $\mathrm{AL}_{\mathrm{ref}}(\mathrm{Sv})$ & $|\Delta \mathrm{AL} / \Delta \mathrm{AC}|$ \\
\hline $\mathrm{ORCA} 05_{L}$ & $1 / 2^{\circ}$ & 6.2 & 1.2 & -1.9 & 1.7 & 0.31 \\
\hline $\mathrm{AGIO}_{L}$ & $1 / 4^{\circ}$ & 15.0 & 2.4 & 3.7 & 1.8 & 0.25 \\
\hline $\mathrm{AGIO}_{E}$ & $1 / 4^{\circ}$ & 15.1 & 2.7 & 2.9 & 1.5 & 0.20 \\
\hline $\mathrm{AGBC}_{E}$ & $1 / 4^{\circ}$ & 10.8 & 2.3 & -1.4 & 1.5 & 0.13 \\
\hline INALT $01_{L}$ & $1 / 10^{\circ}$ & 6.2 & 1.8 & 0.3 & 1.9 & 0.05 \\
\hline $\mathrm{ARC} 112_{L}$ & $1 / 12^{\circ}$ & 16.3 & 2.9 & 1.3 & 1.8 & 0.08 \\
\hline $\mathrm{ARC} 112_{E}$ & $1 / 12^{\circ}$ & 12.6 & 3.8 & 0.9 & 1.8 & 0.07 \\
\hline
\end{tabular}


upstream transport are associated with minimal changes in leakage (squares and stars in Figs. 8a,b). Interexperiment differences in leakage magnitude fall within one standard deviation of the annual-mean reference value, suggesting that differences are well within the internal variability of the system. This decoupling is echoed in the passive tracer values for ARC112 (Fig. $8 \mathrm{~b})$. Convergence of the two leakage quantification methods suggests that Eulerian methods are valid when Indian Ocean waters are appropriately labeled and that any loss of Lagrangian precision is small.

Stronger Agulhas Current transports are reflected in higher volume flux in return current and across the STF (Fig. 8c). Transports across the $\mathrm{STF}_{L}$ and $\mathrm{RC}_{L}$ sections increase with wind stress in all cases, a result that is most pronounced in ARC112 where the largest changes in western boundary transport occur. Although ARC112 shows a higher transport across the STF than expected $(\sim 7.5 \mathrm{~Sv})$, only $6.7 \%$ of these floats cross west of $10^{\circ} \mathrm{E}$, and no substantial undersampling of the leakage occurs. This assertion is supported by the agreement between the Eulerian and Lagrangian leakage estimates. Rather, it is likely that the STF section captures some of the return current transport when meanders occur far to the south (Fig. 3b).

Here, we focus on the Agulhas response to local- and basin-scale processes within the Indian Ocean. However, Durgadoo et al. (2013) show that the large scale can also play a role in determining retroflection behavior, via adjustment of the ACC. To test for any large-scale control over the relationship we see above, we perform a second set of AGIO experiments where the boundary conditions from ORCA05m40 and ORCA05p40 are applied (see Table 2; AGBC). Figures 8d and 8e compare the transport anomalies we see in the AGIO and AGBC sensitivity experiments. In the latter case, the leakage response to changes in upstream inertia is further reduced (Table 6). This suggests that climatological boundary conditions used may cause AGIO to overestimate the link between WBC transport and leakage. This result is consistent with a suggested decoupling. Further, as ARC112 shows only minimal leakage sensitivity, it seems unlikely that boundary condition changes would modify this result. This is supported by the preexisting agreement between the high-resolution models.

\section{e. Retroflection processes}

Derived retroflection position distributions are shown in Fig. 9. Note that our methodology returns an observed pattern consistent with Dencausse et al. (2010), an approximately Gaussian distribution centered around $18.5^{\circ} \mathrm{E}$ (Fig. 9, gray bars). Applying this method to $\mathrm{AGIO}_{r}$ and $\mathrm{ARC112}_{r}$ (Fig. 9, black traces), it is clear
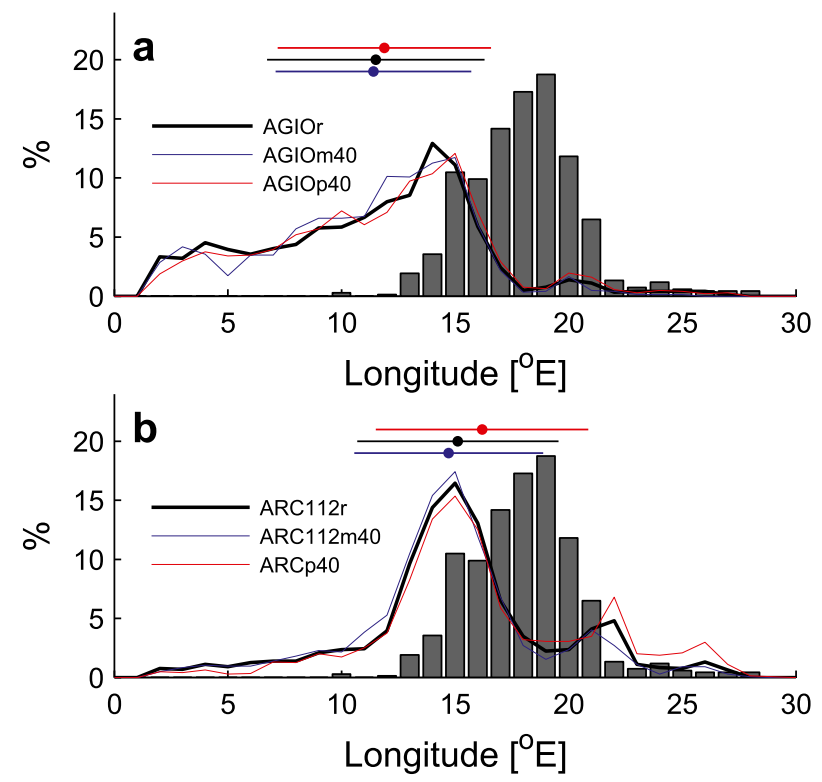

FIG. 9. Probability distribution of retroflection lon for (a) AGIO and (b) ARC112 sensitivity experiments. The 1992-2007 retroflection position distribution for observed values derived from AVISO altimetry is shown in the gray bars. Colored horizontal bars show the std dev and the dots show the mean of the distribution for each sensitivity experiment.

that the former has a more prograded retroflection than that observed, with the westward-skewed distribution eroding the upstream maximum. In contrast, ARC112r has a defined symmetrical peak at $15^{\circ} \mathrm{E}$, about which the distribution is well constrained, more closely resembling observations.

Although the ARC112r and AGIOr reference states clearly differ, Agulhas transport modulation does not drive substantial changes in retroflection distribution in either case. Standard deviations, similar in both models, remain broadly consistent throughout, and, in AGIO, no shift in mean is apparent. In ARC112, increased (decreased) WBC transport makes upstream recirculation events $+4 \%(-2 \%)$ more (less) likely, expressed in the higher (lower) peak at $22^{\circ} \mathrm{S}$ (Fig. 9b). A $1^{\circ}$ eastward shift in the ARC112p40 mean position is attributable to this effect. However, retroflections predominantly still occur around $15^{\circ} \mathrm{E}$ throughout, with no longitudinal shift in the dominant peak (Fig. 9b). Sporadically, large perturbations in the observed Agulhas Current produce extreme retroflection events (van Aken et al. 2013). While upstream recirculations occur in all ARC112 experiments, extreme events (east of $24^{\circ} \mathrm{E}$ ) are rare, and absent from ARC112m40, causing the large negative anomaly in $100-\mathrm{m}$ speed near $\sim 35^{\circ} \mathrm{S}$ seen in Fig. 5b.

Figure 10 shows the retroflection vorticity balance for the top $300 \mathrm{~m}$ of ARC112. In the current core, high 

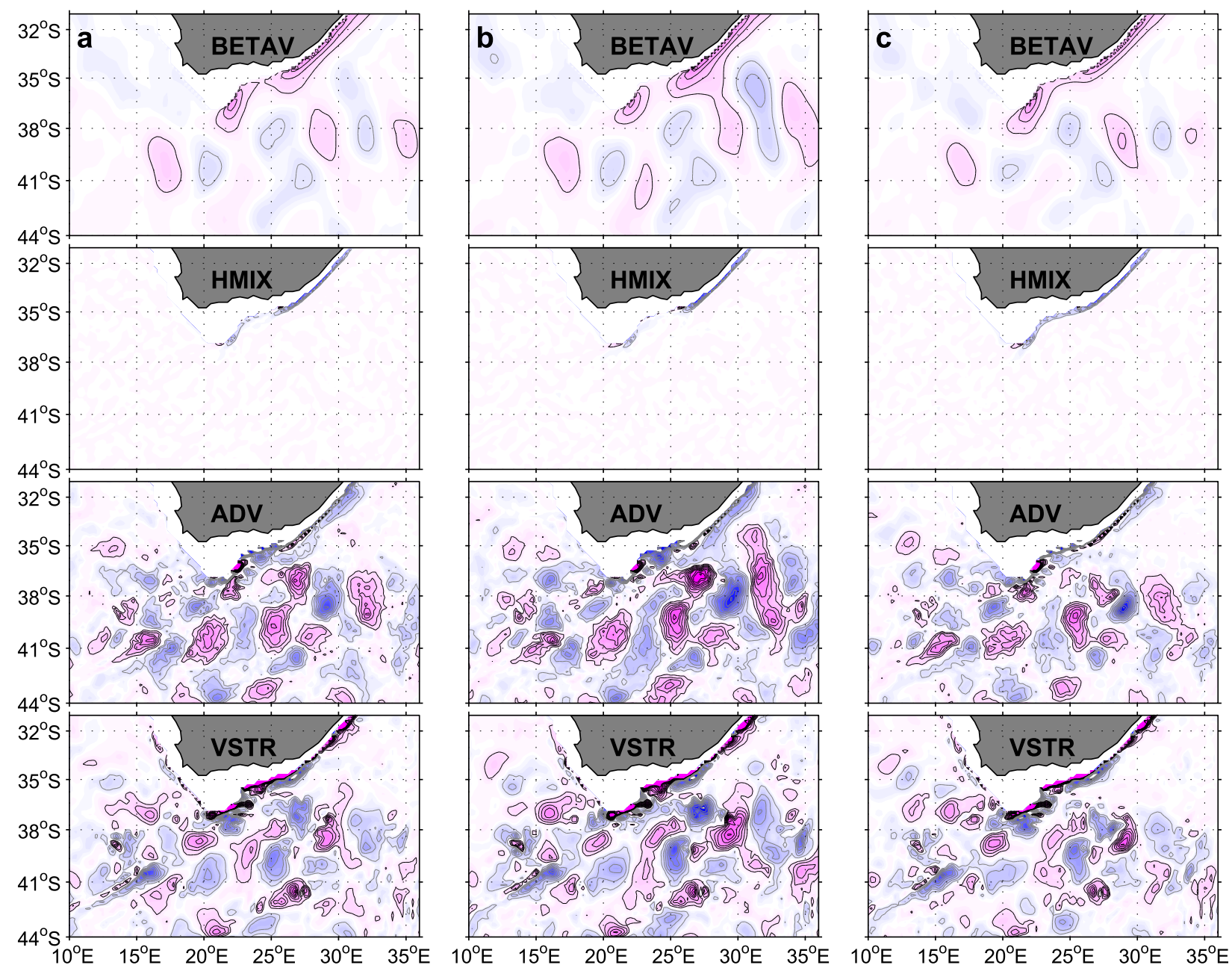

FIG. 10. Depth-integrated vorticity balance terms for the top $300 \mathrm{~m}$ of ARC112 , derived via (3)-(5). (a)-(c) The fields for the ARC112r, ARC112p40, and ARC112m40 experiments, respectively. BETA, HMIX, ADV, and VSTR are contoured at $4 \times 10^{-12} \mathrm{~s}^{-2}$ intervals. Negative (positive) vorticity regions are contoured in gray (black) and shaded blue (purple).

meridional velocity produces a strong $\beta$ effect. In general, this and vortex stretching are balanced by advection (Fig. 10a). The viscous stress term is small throughout, but increases at the western boundary due to steep topography and the Smagorinsky parameterization (Smagorinsky 1963). However, even here, HMIX is dominated by ADV, VSTR, and BETAV terms. Small positive values of HMIX inshore of the current at the shelf break are indicative of an inertial overshoot, consistent with the Boudra and Chassignet (1988) experiment E11. This effect becomes stronger as inertia increases (Fig. 10b). Positive vortex stretching inshore of the current is characteristic of isopycnal shoaling (Boudra and Chassignet 1988). However, despite an increased overshoot in ARC112p40 (Fig. 10b; HMIX), there is an interaction with topography at the tip of the Agulhas Bank in all experiments.
The retroflection is predominantly governed by advection and vortex stretching, with the $\beta$ effect playing a small role in the return current meanders. Notably, the vortex stretching, advection, and $\beta$ terms along $40^{\circ} \mathrm{S}$ strengthen at increased inertia, representative of increased return current flow when the Agulhas Current transport is high. Well-defined VSTR and ADV patterns around the Agulhas Plateau at $26^{\circ} \mathrm{E}$ strengthen with the current transport, indicating a potentially strong topographical control downstream of the retroflection (Matano 1996; Speich et al. 2006).

Agulhas rings, the mechanism via which most leakage occurs, form at the retroflection due to mixed barotropic (BT) and baroclinic (BC) instability (Chassignet and Boudra 1988). Indicators for BT and BC can be derived from the potential [(6)] and kinetic energy [(7)] conversion terms, which we integrate over the top $1000 \mathrm{~m}$ 
(Biastoch and Krauss 1999; Tsugawa and Hasumi 2010). Primed values represent anomalies from the five daily mean horizontal velocities $\bar{u} / \bar{v}$ and potential density $\bar{\rho}$. The horizontal average of the potential density across the domain represents the reference state $\tilde{\rho}$ :

$$
\begin{gathered}
g \iiint_{H}^{0} \frac{\overline{u^{\prime} \rho^{\prime}} \partial \bar{\rho} / \partial x+\overline{v^{\prime} \rho^{\prime}} \partial \bar{\rho} / \partial y}{d \tilde{\rho} / d z} d V \text { and } \\
-\iiint_{H}^{0}\left[\overline{u^{\prime} u^{\prime}} \frac{\partial \bar{u}}{\partial x}+\overline{u^{\prime} v^{\prime}}\left(\frac{\partial \bar{u}}{\partial y}+\frac{\partial \bar{v}}{\partial x}\right)+\overline{v^{\prime} v^{\prime}} \frac{\partial \bar{v}}{\partial y}\right] d V .
\end{gathered}
$$

Barotropic instability characterizes much of the region bounded by the $\mathrm{ARC11}_{r}$ retroflection (Fig. 11a). The shelf break, Agulhas Bank, and retroflection extremity, the likely site of ring formation, show an increased propensity for eddy generation, reflected in high BT and BC values (Fig. 11b). Spatially integrated values (Fig. 11c) show that increased inertia drives increased instability in the upstream current around the shelf break, consistent with the large EKE changes here (Fig. 6). Downstream, baroclinic instability increases, but barotropic changes are smaller, suggesting that ring formation may not be as heavily impacted. Notably, downstream values are lower at reduced wind stress, despite inertial theory suggesting a stronger leakage in this case. Increases in upstream BT are echoed by large negative anomalies in the return current, suggesting that eddies are increasingly incorporated into the mean flow here when flow strengthens.

\section{Discussion}

Sverdrup dynamics dictate that, to the first order, western boundary transport is determined by the zonally integrated wind stress curl across an ocean basin. However, our results show that, although the Agulhas Current responds linearly to wind stress north of $32.5^{\circ} \mathrm{S}$, the magnitude of the response differs from Sverdrup estimates. Biastoch et al. (2009b) previously noted this discrepancy, ascribing it to topographical shielding (Matano et al. 2002) and eddy-mean interactions (Biastoch et al. 2009a). Here, we expand on this, demonstrating that on decadal time scales, transport anomalies generated by upstream trade wind variability can propagate southward under the influence of western boundary inertia, reaching the retroflection despite no modification of the forcing field at this latitude. Consequently, although intensified trade winds may result in a stronger Agulhas Current, the exact response cannot be directly inferred (Biastoch et al. 2009b), emphasizing the need for direct monitoring (Beal et al. 2009).

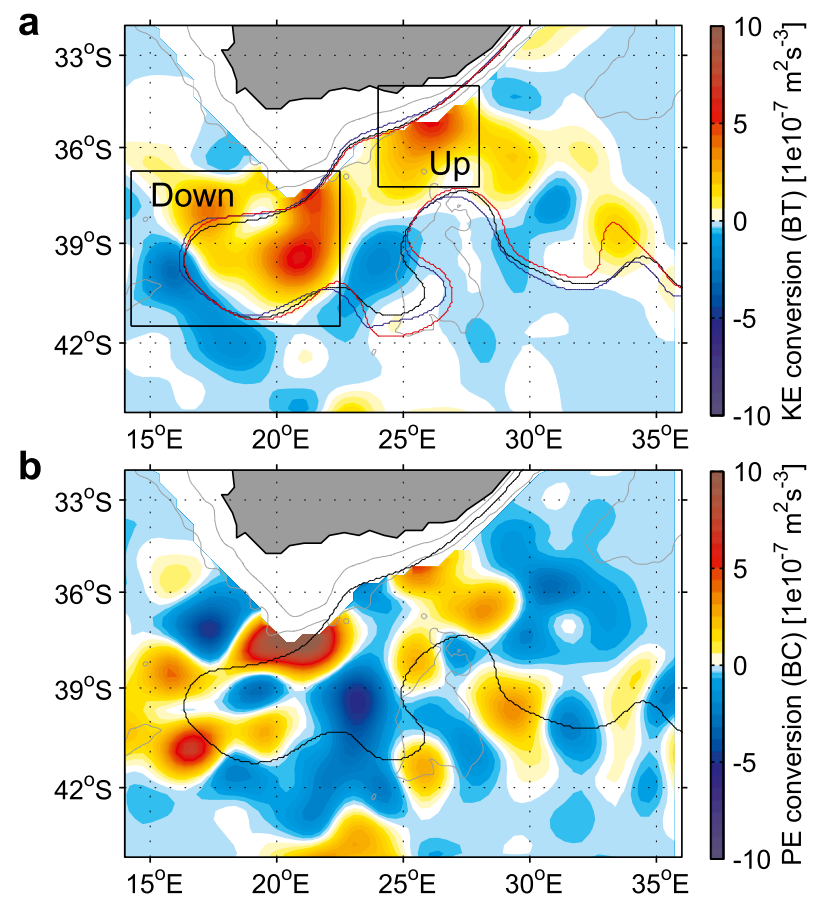

C

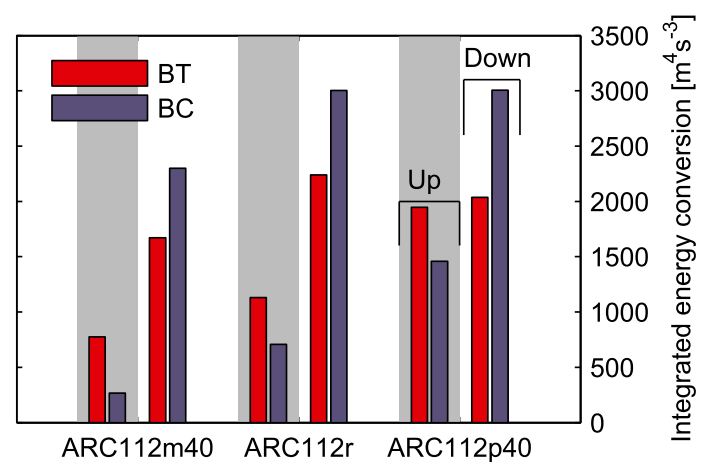

FIG. 11. Spatial distribution of depth-integrated (a) BT and (b) $\mathrm{BC}$ instability in the top $1000 \mathrm{~m}$ of the $\mathrm{ARC} 112_{r}$ experiment, inferred from the kinetic and potential energy conversion terms. The black, red and blue contours track the 20 -yr mean retroflection positions for ARC112r, ARC112m40, and ARC112p40 experiments, respectively. Gray contours show the 400- and 3000-m isobaths. (c) The values of the BC and BT terms, integrated across the upstream (Up) and downstream (Down) boxes, are summarized.

Model behavior in turbulent regions is highly sensitive to numerical choices (Backeberg et al. 2009; Barnier et al. 2006). For robustness, we investigate the dynamical link between the Agulhas Current and leakage using two model platforms: ROMS and NEMO. While model behavior differs at lower resolution (eddy permitting and below), the sensitivity of the Agulhas leakage to incoming transport invariably decreases as the resolution becomes finer. In the eddy-resolving regime, the models converge, and the two configurations (ARC112 and INALT01) present a common response: one where 
trade wind-driven Agulhas Current variability has no significant effect on the leakage.

The Agulhas retroflection mediates the division of the Agulhas Current into the eastward return current and westward leakage components, the latter being of primary climatic interest (de Ruijter et al. 1999; Beal et al. 2011). Key to retroflection dynamics is the balance between viscosity and inertia (Dijkstra and de Ruijter 2001). It has been suggested that, at $14^{\circ}$, ROMS may be overly viscous (van Sebille et al. 2010a). However, low Ekman numbers and HMIX terms imply inertially governed retroflections in both AGIO and ARC112. The vorticity balance we derive for the latter shows a pattern consistent with Boudra and Chassignet (1988), specifically, an inertial overshoot associated with inshore isopycnal doming and a retroflection governed by relative vorticity advection and vortex stretching. However, in our simulations, a stronger inertial overshoot does not result in the earlier retroflection suggested by Ou and de Ruijter (1986), due to continued topographical interaction with the Agulhas Bank and Agulhas Plateau. Subsequently, upstream changes in inertia are reflected in the stronger vortex stretching and advection terms in the first meander of the return current, symptomatic of the increased transport here.

Control of the retroflection position by bathymetry has been noted both in previous numerical model studies (Matano 1996; Speich et al. 2006) and observations (Dencausse et al. 2010). In AGIO, we see that substantial smoothing of this bathymetry can reduce the angle of the shelf break, and the prominence of the Agulhas Bank minimizes the propensity for inertial overshoot, permitting an overly westward retroflection and an enhanced leakage. However, a comparative immobile retroflection position, as seen in ARC112, is consistent with modern observations, which show that, excepting the 2001 extreme event, it has remained remarkably stable since 1992 (Dencausse et al. 2010; Backeberg et al. 2012). Further support comes from paleoceanographic studies that suggest Last Glacial Maximum retroflection longitudes near to the present position (Franzese et al. 2009).

Chassignet and Boudra (1988) show that ring formation occurs through mixed barotropic-baroclinic instability. Tsugawa and Hasumi (2010) suggest that barotropic instability may drive increased Agulhas variability, through Natal pulses. We note a similar upstream response here, at higher inertia. While Biastoch and Krauss (1999) find that the retroflection is governed by baroclinic instability, it is the transfer from mean to kinetic energy (BT) that appears key to ring formation (Chassignet and Boudra 1988). Here, we find this to be near constant in the retroflection loop, and increased upstream eddy production, reflected in regional EKE anomalies, is incorporated back into the mean in the return current.

Previous comparisons of Eulerian and Lagrangian leakage estimates find that the former approach can substantially underestimate volume flux (van Sebille et al. 2010b). By introducing a passive tracer, we remove this constraint and the methodologies converge on a common flux value where the retroflection is more realistic (i.e., in ARC112). In contrast, where overly westward retroflection positions occur, Lagrangian floats are unable to recirculate, causing a leakage overestimation of $5 \mathrm{~Sv}$.

The semicontinuous subtropical front is not a barrier to southward flux (Dencausse et al. 2011). Le Bars et al. (2012) identify a turbulent retroflection regime, where leakage is asymptotically limited by increased crossfrontal mixing in the return current. Under intensified trade winds we note a stronger southward flux at the retroflection and greatly increased EKE along the subtropical front. While our experiments differ from Le Bars et al. (2012), as we do not modify the westerly winds, our results suggest the possibility of inertially driven increases in southward export of Indian Ocean waters.

Two recent hindcast studies have explored the longterm behavior of the Agulhas system (Biastoch et al. 2009b; Rouault et al. 2009). While they agree on a leakage increase since the 1980s, they record respective negative and positive trends in Agulhas Current transport. It has been argued that the anticorrelation seen in Biastoch et al. (2009b) is causal (van Sebille et al. 2009). However, the results presented here suggest that this may not be the case. The models used here are similar to the Rouault et al. (2009) (SAfE) and Biastoch et al. (2009b) (AG01) configurations (section 2b), and the interannual forcing applied (Table 3, suffix $i$ ) is consistent with that used in the latter. Under this forcing, all the models discussed here show long-term trends consistent with AG01. However, physically, $\mathrm{AGIO}_{i}$ differs little from SAfE, suggesting that the differing trends seen between Rouault et al. (2009) and Biastoch et al. (2009b) may be attributable to the choice of forcing and/or boundary conditions.

Recent intensification of the westerly winds has been documented in observations and coupled models (Swart and Fyfe 2012). Durgadoo et al. (2013) find that the leakage responds strongly to intensified westerlies, increasing in magnitude despite no immediate change in Agulhas transport at $32^{\circ} \mathrm{S}$. Here, we show a complementary result: Agulhas Current transport responds strongly to trade wind intensity, with minimal change in leakage. Having established mechanisms by which the two systems can vary independently, we suggest that, while correlations between them may exist in the short term, they may 
not be indicative of a reliable dynamical connection. Rather they arise with changes in both the trades and westerlies part of the larger atmospheric circulation.

Observations and reanalysis products suggest that Indian Ocean winds are intensifying (Han et al. 2010; Gillett and Thompson 2003; Swart and Fyfe 2012), producing an attendant response in Agulhas mesoscale variability (Backeberg et al. 2012). Comparing the kinetic energy anomalies for ARC112p40 with observed trends (Backeberg et al. 2012) yields clear similarities. A common increase in EKE and MKE in the NEMC, the increased (decreased) EKE in the north (south) of the MZC, and a mean intensification in the northern Agulhas Current suggests that the observed responses are dynamically attributable to trade wind intensification. South of $25^{\circ} \mathrm{S}$, our anomalies do not match the observed trend. Therefore, it is unsurprising that we cannot represent the variability observed here.

Although coherent in its southern reaches, the Agulhas Current carries the imprint of mesoscale variability generated around Madagascar. Multiple studies have linked eddy generation in the MZC and SEMC to Agulhas ring formation (Penven et al. 2006b; Schouten et al. 2002). Here, we induce pronounced changes in source region EKE, and it is surprising to find that the leakage is minimally affected. However, in idealized studies, Pichevin et al. (1999) show that upstream current meanders have no influence on ring generation, a result consistent with the observed discrepancy between ring formation, $5 \pm$ $1 \mathrm{yr}^{-1}$ (Schouten et al. 2002), and Natal pulse rates, $1.6 \mathrm{yr}^{-1}$ (Rouault and Penven 2011). Similarly, upstream transport pulses may accelerate ring generation, but do not impact ring formation rates (Pichevin et al. 1999). Further, OGCM experiments confirm that excluding source region variability from eddy-resolving models affects ring path and timing, but does not produce a change in leakage (Biastoch et al. 2008c).

As observations show an increase in retroflection turbulence since 1993, and hindcast experiments show a recent increase in Agulhas leakage, it has been suggested that altimetry-derived EKE may be used as a proxy for interbasin flux (Backeberg et al. 2012). However, Durgadoo et al. (2013) showcase where increased turbulence is associated with decreased interbasin flux, and here we show that changes in EKE do not mandate any leakage change, suggesting that the two quantities do not have an obvious relationship.

The Agulhas Current time series (ACT) array (Beal et al. 2009) is designed to produce a hydrographic record of the Agulhas Current that can be used to calibrate a coincident altimetry track for long-term monitoring. Because of the inferred anticorrelation between current transport and leakage (van Sebille et al. 2009), it has been suggested that ACT may provide a proxy for the latter (van Sebille et al. 2010a). This is an attractive proposition, as annual estimates for the leakage are hard to derive from in situ observations. In reality, it is unlikely that the trade and westerly winds will vary independently, as both are part of the large-scale climate system. However, the apparent freedom with which the Agulhas Current can change, with little downstream consequence necessitates treating any correlation with a degree of skepticism. In this regard, the ACT array becomes necessary in establishing a long-term Agulhas Current time series, but efforts toward direct monitoring of the Agulhas leakage remain essential.

\section{Summary and conclusions}

Four model configurations, of varying resolution, have been used to quantify the response of the Agulhas leakage to changes in the Agulhas Current, driven by changes in the wind stress north of $32.5^{\circ} \mathrm{S}$. This response has been investigated using complementary methodologies based on Lagrangian virtual floats and Eulerian passive tracer flux. We show that an intensification of the trade winds drives a stronger flow in both the tropical and subtropical gyres. This is reflected in the transport and in the Agulhas source regions and the modification of the eddy variability in MZC and SEMC. The combined contributions from the source regions produce Agulhas Current transport anomalies at $32^{\circ} \mathrm{S}$, which persist into the retroflection under inertia.

We find that changes in Agulhas Current transport have a diminishing influence on the Agulhas leakage as the resolution increases. In the eddy-resolving case, model behavior converges and, on a multidecadal time scale, annual-mean changes in the Agulhas Current exceeding $\pm 8 \mathrm{~Sv}$ elicit no significant change in leakage magnitude. This behavior is confirmed through complementary Eulerian and Lagrangian leakage quantification methods, which converge as retroflection position improves.

Trade wind stress anomalies imposed in the sensitivity experiments induce a variability greater than twice the annual standard deviation seen in the 1948-2007 CORE v. $2 b$ reanalysis winds. From this, we conclude that, during this period, the modification of the mean transport of the Agulhas Current by the trade winds has a minimal effect on the annual-mean interbasin flux. Rather, it is more likely that changes in the magnitude of the leakage are predominantly the result of the modulation of the wind stress curl in the latitude of the westerly winds (Durgadoo et al. 2013).

Previous hindcast experiments present a conflicting picture of the dynamical link between the Agulhas Current and leakage (Biastoch et al. 2009b; Rouault 
et al. 2009; van Sebille et al. 2009). Under the interpretation presented here, these results can be reconciled. The interannual experiments performed here show a common weakening in the Agulhas Current with time. However, we show that variability in the trade winds can give rise to a strengthening or weakening of the Agulhas Current, with no consequence for the Agulhas leakage. As the Agulhas leakage is driven by the westerly winds (Durgadoo et al. 2013), we suggest that these trends arise as a consequence of the forcing products used and that correlations between upstream transport and Agulhas leakage may not be indicative of a dynamical link. While observational arrays may be able to exploit these correlations, their potential transience should be reconsidered.

Acknowledgments. This work was funded by the European Community's Seventh Framework Programme FP7/2007-2013-Marie-Curie "GATEWAYS" ITN, Grant Agreement 238512, and the International Centre for Education, Marine and Atmospheric Sciences over Africa (ICEMASA). J.V.D. and A.B. acknowledge funding by the Bundesministerium für Bildung und Forschung project SPACES 03G0835A. Simulations were performed at DST/CSIR CHPC Cape Town, Stuttgart (HLRS) and CAU Kiel (NESH). Altimetry data were obtained online (from http://www.aviso.altimetry.fr/en/ home.html). We thank Dr. Julie Deshayes for assistance configuring PAGO (http://www.whoi.edu/science/PO/ pago). We thank the two reviewers for their constructive comments, which have improved the analysis and interpretation in this manuscript.

\section{REFERENCES}

Backeberg, B. C., and C. J. C. Reason, 2010: A connection between the South Equatorial Current north of Madagascar and Mozambique Channel eddies. Geophys. Res. Lett., 37, L04604, doi:10.1029/2009GL041950.

— L L. Bertino, and J. Johannessen, 2009: Evaluating two numerical advection schemes in HYCOM for eddy-resolving modelling of the Agulhas Current. Ocean Sci., 5, 173-190, doi:10.5194/os-5-173-2009.

_- P. Penven, and M. Rouault, 2012: Impact of intensified Indian Ocean winds on mesoscale variability in the Agulhas system. Nat. Climate Change, 2, 608-612, doi:10.1038/nclimate1587.

Barnier, B., and Coauthors, 2006: Impact of partial steps and momentum advection schemes in a global ocean circulation model at eddy-permitting resolution. Ocean Dyn., 56, 543567, doi:10.1007/s10236-006-0082-1.

Beal, L. M., P. Cipollini, and J. Lutjeharms, 2009: ACT: Towards a multi-decadal index of Agulhas Current transport. Proc. OceanObs '09, Venice, Italy, ESA, 1-3. [Available online at http://www.oceanobs09.net/proceedings/ac/FCXNL-09A021821878-1-ac2b01.pdf.]

- W. P. M. de Ruijter, A. Biastoch, R. Zahn, and SCOR/ WCRP/IAPSO Working Group 136, 2011: On the role of the
Agulhas system in ocean circulation and climate. Nature, 472, 429-436, doi:10.1038/nature09983.

Biastoch, A., and W. Krauss, 1999: The role of mesoscale eddies in the source regions of the Agulhas Current. J. Phys. Oceanogr., 29, 2303-2317, doi:10.1175/1520-0485(1999)029<2303: TROMEI $>2.0 . \mathrm{CO} ; 2$.

—, C. Böning, J. Getzlaff, J.-M. Molines, and G. Madec, 2008a: Causes of interannual-decadal variability in the meridional overturning circulation of the midlatitude North Atlantic Ocean. J. Climate, 21, 6599-6615, doi:10.1175/ 2008JCLI2404.1.

- _ _ , and J. Lutjeharms, 2008b: Agulhas leakage dynamics affects decadal variability in Atlantic overturning circulation. Nature, 456, 489-492, doi:10.1038/nature07426.

—, J. Lutjeharms, C. Böning, and M. Scheinert, 2008c: Mesoscale perturbations control inter-ocean exchange south of Africa. Geophys. Res. Lett., 35, L20602, doi:10.1029/ 2008GL035132.

— L. Leal, J. Lutjeharms, and T. Casal, 2009a: Variability and coherence of the Agulhas Undercurrent in a high-resolution ocean general circulation model. J. Phys. Oceanogr., 39, 24172435, doi:10.1175/2009JPO4184.1.

, C. Böning, F. U. Schwarzkopf, and J. Lutjeharms, 2009b: Increase in Agulhas leakage due to poleward shift of Southern Hemisphere westerlies. Nature, 462, 495-498, doi:10.1038/ nature 08519 .

Blanke, B., and S. Raynaud, 1997: Kinematics of the Pacific Equatorial Undercurrent: An Eulerian and Lagrangian approach from GCM results. J. Phys. Oceanogr., 27, 1038-1053, doi:10.1175/1520-0485(1997)027<1038:KOTPEU>2.0.CO;2.

Boebel, O., T. Rossby, J. Lutjeharms, W. Zenk, and C. Barron, 2003: Path and variability of the Agulhas Return Current. DeepSea Res. II, 50, 35-56, doi:10.1016/S0967-0645(02)00377-6.

Boudra, D., and W. de Ruijter, 1986: The wind-driven circulation of the South Atlantic-Indian Ocean-II. Experiments using a multi-layer numerical model. Deep-Sea Res. I, 33, 447-483, doi:10.1016/0198-0149(86)90126-3.

_- and E. Chassignet, 1988: Dynamics of Agulhas retroflection and ring formation in a numerical model. Part I: The vorticity balance. J. Phys. Oceanogr., 18, 280-303, doi:10.1175/ 1520-0485(1988)018<0280:DOARAR > 2.0.CO;2.

Bryden, H., L. Beal, and L. Duncan, 2005: Structure and transport of the Agulhas Current and its temporal variability. J. Oceanogr., 61, 479-492, doi:10.1007/s10872-005-0057-8.

Cai, W., 2006: Antarctic ozone depletion causes an intensification of the Southern Ocean super-gyre circulation. Geophys. Res. Lett., 33, L03712, doi:10.1029/2005GL024911.

Chassignet, E., and D. Boudra, 1988: Dynamics of Agulhas retroflection and ring formation in a numerical model. Part II: Energetics and ring formation. J. Phys. Oceanogr., 18, 304-319, doi:10.1175/1520-0485(1988)018<0304:DOARAR > 2.0.CO;2.

— Gulf Stream separation. Proc. 12th 'Aha Huliko'a Hawaiian Winter Workshop, Honolulu, HI, University of Hawai'i at Mānoa, 39-43. [Available online at http://www.soest.hawaii. edu/PubServices/2001pdfs/Chassignet.pdf.]

Chelton, D., A. Szoeke, M. Schlax, K. Naggar, and N. Siwertz, 1998: Geographical variability of the first baroclinic Rossby radius of deformation. J. Phys. Oceanogr., 28, 433-460, doi:10.1175/ 1520-0485(1998)028<0433:GVOTFB > 2.0.CO;2.

Debreu, L., C. Vouland, and E. Blayo, 2008: AGRIF: Adaptive Grid Refinement in Fortran. Comput. Geosci., 34, 8-13, doi:10.1016/j.cageo.2007.01.009. 
Dencausse, G., M. Arhan, and S. Speich, 2010: Spatio-temporal characteristics of the Agulhas Current retroflection. Deep-Sea Res. I, 57, 1392-1405, doi:10.1016/j.dsr.2010.07.004.

,$- \ldots$, and $—, 2011$ : Is there a continuous subtropical front south of Africa? J. Geophys. Res., 116, C02027, doi:10.1029/ 2010JC006587.

de Ruijter, W., 1982: Asymptotic analysis of the Agulhas and Brazil Current systems. J. Phys. Oceanogr., 12, 361-373, doi:10.1175/ 1520-0485(1982)012<0361:AAOTAA > 2.0.CO;2.

- , and D. Boudra, 1985: The wind-driven circulation in the South Atlantic-Indian Ocean-I. Numerical experiments in a one-layer model. Deep-Sea Res. I, 32, 557-574, doi:10.1016/ 0198-0149(85)90044-5.

—- A. Biastoch, S. Drijfhout, J. Lutjeharms, R. Matano, T. Pichevin, P. van Leeuwen, and W. Weijer, 1999: IndianAtlantic interocean exchange: Dynamics, estimation and impact. J. Geophys. Res., 104, 20 885-20910, doi:10.1029/ 1998JC900099.

—, H. Aken, E. Beier, J. Lutjeharms, R. Matano, and M. Schouten, 2004: Eddies and dipoles around south Madagascar: Formation, pathways and large-scale impact. Deep-Sea Res. I, 51, 383-400, doi:10.1016/j.dsr.2003.10.011.

Dijkstra, H., and W. de Ruijter, 2001: On the physics of the Agulhas Current: Steady retroflection regimes. J. Phys. Oceanogr., 31, 2971-2985, doi:10.1175/1520-0485(2001)031<2971: OTPOTA $>2.0 . \mathrm{CO} ; 2$.

Doglioli, A., M. Veneziani, B. Blanke, S. Speich, and A. Griffa, 2006: A Lagrangian analysis of the Indian-Atlantic interocean exchange in a regional model. Geophys. Res. Lett., 33, L14611, doi:10.1029/2006GL026498.

Donohue, K., and J. Toole, 2003: A near-synoptic survey of the southwest Indian Ocean. Deep-Sea Res. II, 50, 1893-1931, doi:10.1016/S0967-0645(03)00039-0.

Durgadoo, J. V., B. R. Loveday, C. J. C. Reason, P. Penven, and A. Biastoch, 2013: Agulhas leakage predominantly responds to the Southern Hemisphere westerlies. J. Phys. Oceanogr., 43, 2113-2131, doi:10.1175/JPO-D-13-047.1.

Fairall, C., E. Bradley, D. Rogers, and J. Edson, 1996: Bulk parameterization of air-sea fluxes for tropical ocean-global atmosphere coupled-ocean atmosphere response experiment. J. Geophys. Res., 101, 3747-3764, doi:10.1029/95JC03205.

Fichefet, T., and M. Maqueda, 1997: Sensitivity of a global sea ice model to the treatment of ice thermodynamics and dynamics. J. Geophys. Res., 102, 12 609-12 646, doi:10.1029/97JC00480.

Franzese, A., S. Hemming, and S. Goldstein, 2009: Use of strontium isotopes in detrital sediments to constrain the glacial position of the Agulhas retroflection. Paleoceanography, 24, PA2217, doi:10.1029/2008PA001706.

Gillett, N. P., and D. Thompson, 2003: Simulation of recent Southern Hemisphere climate change. Science, 302, 273-275, doi:10.1126/science. 1087440.

Godfrey, J., 1989: A Sverdrup model of the depth-integrated flow for the World Ocean, allowing for island circulation. Geophys. Astrophys. Fluid Dyn., 45, 89-112, doi:10.1080/ 03091928908208894.

Gordon, A., 1986: Interocean exchange of thermocline water. J. Geophys. Res., 91, 5037-5046, doi:10.1029/JC091iC04p05037.

Haidvogel, D., and A. Beckmann, 1999: Numerical Ocean Circulation Modeling. Series on Environmental Science and Management, Vol. 2, World Scientific, 344 pp.

Hall, C., and J. R. E. Lutjeharms, 2011: Cyclonic eddies identified in the Cape Basin of the South Atlantic Ocean. J. Mar. Syst., 85, 1-10, doi:10.1016/j.jmarsys.2010.10.003.
Han, W., and Coauthors, 2010: Patterns of Indian Ocean sea-level change in a warming climate. Nat. Geosci., 3, 546-550, doi:10.1038/ngeo901.

Large, W., and S. Yeager, 2009: The global climatology of an interannually varying air-sea flux data set. Climate Dyn., 33, 341-364, doi:10.1007/s00382-008-0441-3.

_ J. McWilliams, and S. Doney, 1994: Oceanic vertical mixing: A review and a model with a nonlocal boundary layer parameterization. Rev. Geophys., 32, 363-403, doi:10.1029/ 94RG01872.

Le Bars, D., W. de Ruijter, and H. A. Dijkstra, 2012: A new regime of the Agulhas Current retroflection: Turbulent choking of Indian-Atlantic leakage. J. Phys. Oceanogr., 42, 1158-1172, doi:10.1175/JPO-D-11-0119.1.

Lee, S.-K., W. Park, E. van Sebille, M. O. Baringer, C. Wang, D. B. Enfield, S. G. Yeager, and B. P. Kirtman, 2011: What caused the significant increase in Atlantic Ocean heat content since the mid-20th century? Geophys. Res. Lett., 38, L17607, doi:10.1029/2011GL048856.

Lutjeharms, J., and J. Cooper, 1996: Interbasin leakage through Agulhas Current filaments. Deep-Sea Res. I, 43, 213-215, doi:10.1016/0967-0637(96)00002-7.

Madec, G., 2008: NEMO ocean engine. Institut Pierre Simon Laplace Note du Pôle de modélisation 27, 367 pp.

Marchesiello, P., J. McWilliams, and A. Shchepetkin, 2001: Open boundary conditions for long-term integration of regional oceanic models. Ocean Modell., 3, 1-20, doi:10.1016/ S1463-5003(00)00013-5.

—, L. Debreu, and X. Couvelard, 2009: Spurious diapycnal mixing in terrain-following coordinate models: The problem and a solution. Ocean Modell., 26, 156-169, doi:10.1016/ j.ocemod.2008.09.004.

Matano, R. P., 1996: A numerical study of the Agulhas retroflection: The role of bottom topography. J. Phys. Oceanogr., 26,2267-2279, doi:10.1175/1520-0485(1996)026<2267: ANSOTA $>2.0 . \mathrm{CO} ; 2$.

— E. Beier, P. Strub, and R. Tokmakian, 2002: Large-scale forcing of the Agulhas variability: The seasonal cycle. J. Phys. Oceanogr., 32, 1228-1241, doi:10.1175/1520-0485(2002)032<1228: LSFOTA $>2.0 . \mathrm{CO} ; 2$.

Nauw, J. J., H. M. van Aken, A. Webb, J. R. E. Lutjeharms, and W. de Ruijter, 2008: Observations of the southern East Madagascar Current and undercurrent and countercurrent system. J. Geophys. Res., 113, C08006, doi:10.1029/ 2007JC004639.

Ou, H., and W. de Ruijter, 1986: Separation of an inertial boundary current from a curved coastline. J. Phys. Oceanogr., 16, 280-289, doi:10.1175/1520-0485(1986)016<0280: SOAIBC $>2.0 . \mathrm{CO} ; 2$.

Peeters, F., R. Acheson, G. Brummer, W. de Ruijter, R. Schneider, G. Ganssen, E. Ufkes, and D. Kroon, 2004: Vigorous exchange between the Indian and Atlantic Oceans at the end of the past five glacial periods. Nature, 430, 661-665, doi:10.1038/ nature 02785 .

Penven, P., N. Chang, and F. Shillington, 2006a: Modelling the Agulhas Current using SAfE (Southern Africa Experiment). Geophysical Research Abstracts, Vol. 8, Abstract 04225. [Available online at http://meetings.copernicus.org/ www.cosis.net/abstracts/EGU06/04225/EGU06-J-04225. pdf.]

_ J. Lutjeharms, and P. Florenchie, 2006b: Madagascar: A pacemaker for the Agulhas Current system. Geophys. Res. Lett., 33, L17609, doi:10.1029/2006GL026854. 
P. Marchesiello, L. Debreu, and J. Lefèvre, 2008: Software tools for pre- and post-processing of oceanic regional simulations. Environ. Modell. Software, 23, 660-662, doi:10.1016/ j.envsoft.2007.07.004.

Pichevin, T., D. Nof, and J. Lutjeharms, 1999: Why are there Agulhas rings? J. Phys. Oceanogr., 29, 693-707, doi:10.1175/ 1520-0485(1999)029<0693:WATAR >2.0.CO;2.

Quartly, G. D., and M. A. Srokosz, 2004: Eddies in the southern Mozambique Channel. Deep-Sea Res. II, 51, 69-83, doi:10.1016/ j.dsr2.2003.03.001.

- B. A. de Cuevas, and A. C. Coward, 2013: Mozambique Channel eddies in GCMs: A question of resolution and slippage. Ocean Modell., 63, 56-67, doi:10.1016/j.ocemod.2012.12.011.

Richardson, P., 2007: Agulhas leakage into the Atlantic estimated with subsurface floats and surface drifters. Deep-Sea Res. I, 54, 1361-1389, doi:10.1016/j.dsr.2007.04.010.

Ridderinkhof, H., and W. de Ruijter, 2003: Moored current observations in the Mozambique Channel. Deep-Sea Res. II, 50, 1933-1955, doi:10.1016/S0967-0645(03)00041-9.

Rouault, M., P. Penven, and B. Pohl, 2009: Warming in the Agulhas Current system since the 1980's. Geophys. Res. Lett., 36, L12602, doi:10.1029/2009GL037987.

Rouault, M. J., and P. Penven, 2011: New perspectives on Natal pulses from satellite observations. J. Geophys. Res., 116, C07013, doi:10.1029/2010JC006866.

Schouten, M., W. de Ruijter, and P. van Leeuwin, 2002: Upstream control of Agulhas ring shedding. J. Geophys. Res., 107, 3109, doi:10.1029/2001JC000804.

Shchepetkin, A., and J. McWilliams, 2005: The Regional Oceanic Modeling System (ROMS): A split-explicit, free-surface, topography-following-coordinate oceanic model. Ocean Modell., 9, 347-404, doi:10.1016/j.ocemod.2004.08.002.

Siedler, G., M. Rouault, and J. R. E. Lutjeharms, 2006: Structure and origin of the subtropical South Indian Ocean Countercurrent. Geophys. Res. Lett., 33, L24609, doi:10.1029/ 2006 GL027399.

,,-- A. Biastoch, B. Backeberg, C. J. C. Reason, and J. R. E. Lutjeharms, 2009: Modes of the southern extension of the East Madagascar Current. J. Geophys. Res., 114, C01005, doi:10.1029/2008JC004921.

Smagorinsky, J., 1963: General circulation experiments with primitive equations. Mon. Wea. Rev., 91, 99-164, doi:10.1175/ 1520-0493(1963)091<0099:GCEWTP > 2.3.CO;2.

Speich, S., B. Blanke, and G. Madec, 2001: Warm and cold water routes of an OGCM thermohaline conveyor belt. Geophys. Res. Lett., 28, 311-314, doi:10.1029/2000GL011748.
_ J. R. E. Lutjeharms, P. Penven, and B. Blanke, 2006: Role of bathymetry in Agulhas Current configuration and behaviour. Geophys. Res. Lett., 33, L23611, doi:10.1029/2006GL027157.

Swart, N. C., and J. C. Fyfe, 2012: Observed and simulated changes in the Southern Hemisphere surface westerly wind-stress. Geophys. Res. Lett., 39, L16711, doi:10.1029/2012GL052810.

Swart, S., S. Speich, I. J. Ansorge, G. J. Goni, S. Gladyshev, and J. R. E. Lutjeharms, 2008: Transport and variability of the Antarctic Circumpolar Current south of Africa. J. Geophys. Res., 113, 9014, doi:10.1029/2007JC004223.

Thompson, D. W. J., and S. Solomon, 2002: Interpretation of recent Southern Hemisphere climate change. Science, 296, 895-899, doi:10.1126/science.1069270.

Tsugawa, M., and H. Hasumi, 2010: Generation and growth mechanism of the Natal pulse. J. Phys. Oceanogr., 40, 15971612, doi:10.1175/2010JPO4347.1.

van Aken, H. M., J. R. E. Lutjeharms, M. Rouault, C. Whittle, and W. de Ruijter, 2013: Observations of an early Agulhas Current retroflection event in 2001: A temporary cessation of interocean exchange south of Africa? Deep-Sea Res. I, 72, 1-8, doi:10.1016/j.dsr.2012.11.002.

van der Werf, P., P. van Leeuwin, H. Ridderinkhof, and W. de Ruijter, 2010: Comparison between observations and models of the Mozambique Channel transport: Seasonal cycle and eddy frequencies. J. Geophys. Res., 115, C02002, doi:10.1029/ 2009JC005633.

van Sebille, E., A. Biastoch, P. van Leeuwin, and W. de Ruijter, 2009: A weaker Agulhas Current leads to more Agulhas leakage. Geophys. Res. Lett., 36, L03601, doi:10.1029/2008GL036614.

_ L. Beal, and A. Biastoch, 2010a: Sea surface slope as a proxy for Agulhas Current strength. Geophys. Res. Lett., 37, L09610, doi:10.1029/2010GL042847.

_ P. van Leeuwin, A. Biastoch, and W. de Ruijter, 2010b: Flux comparison of Eulerian and Lagrangian estimates of Agulhas leakage: A case study using a numerical model. Deep-Sea Res. I, 57, 319-327, doi:10.1016/j.dsr.2009.12.006.

Weijer, W., W. de Ruijter, A. Sterl, and S. Drijfhout, 2002: Response of the Atlantic overturning circulation to South Atlantic sources of buoyancy. Global Planet. Change, 34, 293-311, doi:10.1016/S0921-8181(02)00121-2.

Whittle, C., J. R. E. Lutjeharms, C. Duncombe-Rae, and F. Shillington, 2008: Interaction of Agulhas filaments with mesoscale turbulence: A case study. S. Afr. J. Sci., 104, 135-139.

Zharkov, V., and D. Nof, 2008: Agulhas ring injection into the South Atlantic during glacials and interglacials. Ocean Sci., 4, 223-237. 